\title{
The Interannual Variability of Shallow Meridional Overturning Circulation and its association with the South-West Indian Ocean Heat Content variability
}

\author{
Rahul U Pai ( $\square$ rahul.pai@tropmet.res.in ) \\ Indian Institute of Tropical Meteorology \\ Anant Parekh \\ Indian Institute of Tropical Meteorology \\ Jasti S. Chowdary \\ Indian Institute of Tropical Meteorology \\ C. Gnanaseelan \\ Indian Institute of Tropical Meteorology
}

\section{Research Article}

Keywords: Indian Ocean, Shallow Meridional Overturning Circulation, inter annual variability, oceanic Heat content

Posted Date: November 17th, 2021

DOI: https://doi.org/10.21203/rs.3.rs-1029276/v1

License: (9) This work is licensed under a Creative Commons Attribution 4.0 International License. Read Full License 


\section{Abstract}

The present study examines interannual variability of Shallow Meridional Overturning Circulation (SMOC) using century long reanalysis data. The strength of the transport associated with SMOC is calculated by meridional overturning streamfunction. The interannual variability in $\mathrm{SMOC}$ is found maximum between the $5^{\circ} \mathrm{S}$ and $15^{\circ} \mathrm{S}$ and displaying strong signals after 1940s. A year for which the meridional overturning streamfunction detrended anomaly is greater (lesser) its standard deviation is identified as strong (weak) SMOC year. For strong (weak) SMOC year composite displayed more (less) southward transport ( 2.5 Sv) and shown excess (less) subduction over the South Indian Ocean. During strong (weak) years, the excess (less) southward heat transport ( 0.25PW) leads to reduction (increase) in the upper $200 \mathrm{~m}$ Ocean Heat Content (OHC) and sea level over the Southwest Indian Ocean (SWIO). The results obtained are well supported by tide gauge and satellite measured sea level data for the available period. Further analysis reveals that the SMOC variability is primarily driven by change in zonal wind stress south of the equator and displayed association with the Southern Oscillation Index. The Ocean model-based sensitivity experiments confirms that the $\mathrm{OHC}$ variability over SWIO is closely associated with the SMOC variability and is primarily driven by local wind forcing as a response to El Niño Southern Oscillation. However, the role of remote forcing from Pacific through Oceanic pathway over SWIO is absent. Study attempts to provide a comprehensive view on the interannual variability of $\mathrm{SMOC}$ and its linkage to $\mathrm{OHC}$ variability over SWIO during last century.

\section{Introduction}

The Ocean's ability to store and transport heat makes it an important component of the climate system. Large scale surface winds in the Tropical Indian Ocean produce a meridional circulation which plays a crucial role in the heat and salt budget of the Indian Ocean (e.g., Schott et al., 2002, Horii et al., 2013). On an annual scale, the main forcing responsible for Indian Ocean meridional circulation is the southwest monsoon wind stress north of equator (dominated by westerly winds) and easterly winds south of the equator result, the southward Ekman transport in both sides of the equator (Schott et al., 2002). Southward transports connect the upwelling zones in the Northern Hemisphere (primarily off Somalia) and the subduction zone in the southeastern Indian Ocean, forming a Cross Equatorial Cell (CEC, Garternicht and Schott, 1997; Lee and Marotzke, 1997; Miyama et al., 2003). A part of the poleward transported water from the subduction zone is upwelled at Seychelles thermocline ridge forming a shallow Subtropical Cell (STC) in South Indian Ocean. The CEC and STC collectively form the Shallow Meridional Overturning Circulation (SMOC) of the Indian Ocean and are mostly confined to the upper $500 \mathrm{~m}$. Schoenefeldt and Schott (2006) reported that the mean southward transport across the equator by CEC is $6 \mathrm{~Sv}$ and heat transport is $-0.24 \mathrm{PW}\left(1 \mathrm{PW}=10^{15}\right.$ Watts). SMOC variability considerable influences the redistribution of ocean heat, salt by transporting water mass and its properties meridionally between tropics and subtropics (McPhaden and Zhang, 2002, 2004; Zhang and McPhaden, 2006).

Studies reported that the SMOC displays variability from seasonal to decadal time scales (Wang and McPhaden, 2017; Lee, 2004; Schoenfeldt and Schott, 2006). A significant interannual variability in both 
CEC and STC is also reported by several studies (e.g., Schott et al., 2004, Meng et al., 2020). Ruijin et al., (2005) reported that the interannual variability of the meridional heat transport across the equator and sea surface temperature (SST) in the north Indian Ocean are closely related. Horii et al., (2013) studied seasonal to interannual variability of meridional currents using Acoustic Doppler Current Profilers (ADCPs) at the central equatorial Indian Ocean (at $0^{\circ}, 90^{\circ} \mathrm{E}$ ) for the period 2002-2009. A significant correlation ( 0.6) was found between the observed meridional transport and the Niño 3.4 index during the peak phase of El Niño Southern Oscillation (ENSO). They also suggested that the net meridional volume and heat transports found to be more (less) southward when El Niño (La Niña) conditions occurred in the tropical equatorial Pacific. This suggests the importance of remote forcing in modulating the SMOC mainly on the interannual time sale.

A recent study by Meng et al., (2020) found that the CEC and the STC exhibited significant variability on interannual to decadal timescales during 1958-2017 using reanalysis data and the CEC and the STC were negatively correlated during the research period. Chirakova and Webster (2006) studied interannual variability of Indian Ocean heat transport and found that the majority of the variability was associated with Ekman transport with maximum seen between the latitude $10^{\circ} \mathrm{S}$ to $20^{\circ} \mathrm{S}$. Hence the subtropical southern Indian Ocean (SIO) is experiencing variation in heat accumulation, which effect to regional sea level variability. The variability of heat content and sea level in the SIO is strongly influenced by largescale climatic forcing in the Indo-Pacific region. The remote effect on the SIO heat content is possible by oceanic pathway changes in the upper-ocean heat content in the western equatorial Pacific or/and local changes in wind forcing in the SIO atmospheric pathway (Volkov et al., 2020). Lee et al., (2015) concluded that the Indian Ocean has become increasingly important in modulating global climate variability. Volkov et al., (2020) highlighted the complexity of the observed sea-level and heat content variability in the SIO. Above discussion prerequisite for a detailed study of SMOC variability and its impact on heat transport and associated ocean heat content variability of the south Indian Ocean. Considering the spatio-temporal constraints in observational data a detailed understanding of the SMOC variability was not possible. Century long ocean reanalysis data provided unprecedented opportunity to study the variability of SMOC during the last century and its impact on SIO heat content, sea level and temperature variability. This study attempts to understand the interannual variability of SMOC during last century using reanalysis dataset. The study also examines the relative contribution of local wind forcing and remote forcing from the Pacific through ITF over Indian Ocean with the help of model experiments. The linkage between the SMOC variability and South Indian Ocean Heat Content and sea level is also explored. Section 2 discusses the detail of datasets, model based experiments detail and methodology used in the study. The validation of meridional currents of reanalysis data with observations is provided in section 3. Results related to SMOC variability is discussed in section 4 . Section 5 and 6 provides a detail description of the impact of heat transport variability associated with SMOC on heat content, thermocline depth and sea level and the causes of variability, respectively. The summary and conclusion of the study are discussed in section 7.

\section{Datasets Used, Experiment Details And Methodology}




\subsection{Datasets used}

Various observational and reanalysis datasets are used for the present study. Ocean Surface Current Analyses Real-time (OSCAR) upper ocean current based on satellite data for the period of 1993-2009 are used as observed currents for validating model simulated upper ocean currents (https://www.esr.org/research/oscar/data-access/). Sikhakolli et al., (2013) reported that over the Tropical Indian Ocean OSCAR product is able to capture the variability of the well-known surface current systems reasonably well. OSCAR has provided unprecedented information about global upper ocean currents (upper $30 \mathrm{~m}$ averaged). In addition, the in-situ measurements from ADCP mooring deployed by Japan Agency for Marine-Earth Science and Technology (JAMSTEC) at $90^{\circ} \mathrm{E}$ on the equator, offers sub surface observations of monthly horizontal currents are used for validation. The data is available between the depths of 40 and $340 \mathrm{~m}$ with $8 \mathrm{~m}$ vertical resolution for the period November 2000 to March 2009 (Masumoto et al., 2005). The dataset is available at https://www.pmel.noaa.gov/tao/drupal/disdel/.

The ocean reanalysis product, Simple Ocean Data Assimilation (SODA) version 2.2.4 (Carton and Giese, 2008), is used in this study (http://apdrc.soest.hawaii.edu/datadoc/soda_2.2.4.php). It is an extended ocean reanalysis product using the Parallel Ocean Program (POP) ocean model and the National Oceanic and Atmospheric Administration (NOAA)/National Centers for Environmental Prediction Twentieth Century Reconstruction version 2 winds (Giese and Ray, 2011). It provides an estimate of the ocean on a $0.5^{\circ} \times 0.5^{\circ}$ grid with 40 vertical levels for the period of $1871-2010$. Selected reanalysis products span different time periods, overlapping over the last decades of the twentieth century. A summary of recent improvements in ocean reanalysis, along with an evaluation of their uncertainties, is provided by Balmaseda et al., (2015). In addition, data from ORAS4, a reanalysis product of ECMWF is also used (https://www.cen.uni-hamburg.de/en/icdc/data/ocean/easy-init-ocean/ecmwf-ocean-reanalysis-system4-oras4.html). It is forced by the ERA-Interim reanalysis fluxes, uses Nucleus for European Modelling of the Ocean (NEMO) model (Madec, 2008), the horizontal resolution is $1^{\circ}$ in the extra tropics and a meridional resolution of $0.3^{\circ}$ at the equator. It has 42 vertical levels with 18 of them in the first $200 \mathrm{~m}$ and the first level is at $5 \mathrm{~m}$. NEMOVAR assimilates temperature and salinity profiles, and along-track altimeterderived sea-level anomalies. In addition to the above, observed SST and global mean sea-level variations are used to modify the heat and fresh-water budget respectively. Compared to a control ocean model simulation, ORAS4 improves the fit to observations, the interannual variability and seasonal forecast skill (Balmaseda et al., 2013). Recent study by Karmakar et al., (2018) and Motoki and McPhaden (2017), highlighted the credibility of Ocean Reanalysis products with respect to observations.

Met Office Hadley Centre (EN4, Good et al., 2013) (http://www.metoffice.gov.uk/hadobs) ocean analysis and Ishi et al., (2003) (https://www.cen.uni-hamburg.de/en/icdc/data/ocean/ishii.html) historical ocean analysis, temperature and salinity profile data are used to access oceanic heat content variability. Delayed-time monthly mean sea level anomaly (SLA) maps are obtained from the Archiving, Validation, and Interpretation of Satellite Oceanographic Data (AVISO) (Ducet et al., 2000) (ftp://ftp.aviso.altimetry.fr/global/delayed-time/grids/climatology/monthly_mean). They have a spatial 
resolution of $\left(1 / 4^{\circ} \times 1 / 4^{\circ}\right)$ and extend from 1993 to the present. This product is widely used to understand the regional as well as global sea level variability at various time scales (e.g., Unnikrishnan et al., 2015 ; Han et al., 2014). The tide gauge data from the Madagascar station NOSY-BE $\left(13.4^{\circ} \mathrm{S}, 48.3^{\circ} \mathrm{E}\right)$ available for a shorter period (1958-1972) is also used. The data is obtained from https://www.psmsl.org/data/. The 200hpa horizontal winds and Mean Sea Level Pressure (MSLP) datasets from NOAA 20th Century version2 (20CRv2) dataset are used. 20CR data contains objectivelyanalyzed 4-dimensional weather maps and their uncertainty from the late 19th to 21 st century. The dataset is available at $2^{\circ} \times 2^{\circ}$ resolution for the period spanning from 1871-2012. The Coordinated Oceanice Reference Experiments (CORE) framework defines protocols for performing global ocean-sea-ice coupled simulations forced with common atmospheric data sets, using the same bulk formulae. This dataset is just for the interannually varying forcing (IAF), as developed by Large and Yeager (2009) at NCAR. The version 2 of the CORE-IAF (CIAF) is used in the present study (Griffies et al., 2011) (https://data1.gfdl.noaa.gov/nomads/forms/core/COREv2.html). CIAF version 2 for years 1948-2009 (Large and Yeager, 2009) with 6 hourly shortwave and long wave radiation, 10m surface wind fields, specific humidity, air temperature, monthly surface precipitation and annual river runoff are used for model-based experiments.

\subsection{Model and Experiment details}

The ocean general circulation model used in this study is Modular Ocean Model (MOM5), developed and supported by researchers at NOAA's Geophysical Fluid Dynamics Laboratory (GFDL). It emerged from numerical ocean models developed in the 1960's-1980's by Kirk Bryan and Mike Cox at GFDL. The vertical mixing in the model is achieved through the K-Profile Parameterization (KPP) scheme (Large et al., 1994) using local and non-local mixing with Bryan-Lewis background diffusivity (Byran and Lewis, 1979). The model consists of a global grid with horizontal resolution $\sim 0.25^{\circ}$ at the equator and increases to $8-11 \mathrm{~km}$ at higher latitudes. It consists of 50 vertical levels with vertical resolution of the upper 20 levels at $10 \mathrm{~m}$ resolution and gradually changes to a maximum thickness of $\sim 370 \mathrm{~m}$ at $5000 \mathrm{~m}$. The setup is also provided with a realistic topography of $0.5^{\circ}$ resolution, which is derived from the 5 -minute global topography ETOPO5 (Earth Topography-5minute). More descriptive technical aspects of MOM are provided in Griffies et al., (2012).

The global grid is initialized by Levitus (1998) climatology of temperature and salinity profiles. The model is spun up for 50 years to attain a mean state using the climatological forcing (downwelling shortwave and longwave radiation, $10 \mathrm{~m}$ surface winds fields, specific humidity, air temperature, surface pressure and surface precipitation) from NCAR climatology (Large and Yeager, 2004). Following this, a control experiment (CTRL) is carried out using 6 hourly CIAF forcing fields from 1960-2009. Previous studies have assessed the contribution of local and remote forcing on the tropical South Indian Ocean through oceanic pathways with the help of ocean model-based sensitivity experiments (Trenary and Han, 2013; Ummenhofer et al., 2013; Mohapatra et al., 2020). This was achieved by restricting the interannual atmospheric forcing to the Indian Ocean basin, whereas climatological forcing was imposed elsewhere. In this study, sensitivity experiment is also performed to investigate the contribution of the local wind 
forcing over the Indian Ocean to the SMOC variability. Here onwards, this experiment is referred to as IOSMOC. In IOSMOC, the CORE forcing fields are fixed to climatological mean, except the momentum fluxes over the Indian Ocean basin from $30^{\circ} \mathrm{E}-120^{\circ} \mathrm{E}, 30^{\circ} \mathrm{N}-35^{\circ} \mathrm{S}$ are allowed to evolve for the period $1960-$ 2009. Hence, the solutions obtained from IOSMOC will exclude the possible variability impact of remote forcing from Pacific and Atlantic Oceans through ITF and Agulhas retroflection, respectively.

\subsection{Methodology}

To quantify the strength of SMOC meridional overturning stream function is $\Psi(y, z, t)$ estimated.

$$
\Psi(y, z, t)=\int_{z}^{0} \int_{x_{i v}}^{x_{e}} v(x, y, z, t) d x d z
$$

where, $v(\mathrm{x}, \mathrm{y}, \mathrm{z}, \mathrm{t})$ is the meridional velocity which is a function of zonal, meridional, vertical coordinate and time respectively, $x_{e}$ and $x_{w}$ are the eastern and western boundaries (Kanzow et al., 2009). To examine the impact of SMOC variability on the temperature, meridional heat transport is $Q(y, t)$ is calculated from $v$ and potential temperature $(\theta)$ from surface to bottom integrated along the zonal section spanning an ocean basin.

$$
Q(y, t)=\rho C_{p} \int_{z}^{0} \int_{x_{w}}^{x_{x}} \theta v d x d z
$$

where, $\rho$ is the density of ocean water and $C_{p}$ is the specific heat capacity of ocean water at constant pressure (Volkov et al., 2010). Also, the upper ocean heat content from surface to depth is estimated as in the following equation (3),

$\operatorname{OHC}(y, t)=\rho c_{p} \int_{z}^{0} \theta d z$

The variability in SMOC is quantified using the meridional overturning stream function anomaly integrated from surface to $60 \mathrm{~m}$, the depth up to which mean meridional currents are southward. The annual anomaly of meridional overturning stream function is computed by subtracting the long term mean annual meridional overturning stream function. The linear trend is removed from annual anomaly of meridional overturning stream function by detrending the data. The meridional overturning stream function anomaly spanning $50^{\circ} \mathrm{E}$ to $110^{\circ} \mathrm{E}$ and $8^{\circ} \mathrm{S}$ to $15^{\circ} \mathrm{S}$ (hereafter SMOC region) is considered to represent SMOC variability and between the latitudes $5^{\circ} \mathrm{N}$ to the equator (hereafter the CEC region) is considered to represent CEC variability. The difference between SMOC and CEC variability is considered as STC variability. The Southern Oscillation Index (SOI) is estimated as the difference of MSLP anomaly between Tahiti $\left(149^{\circ} \mathrm{W}, 17.5^{\circ} \mathrm{S}\right)$ to Darwin $\left(130^{\circ} \mathrm{E}, 12.4^{\circ} \mathrm{S}\right)$.

\section{Assessment Of Reanalysis Data Of Meridional Currents}

Figure.1a, b displays scatter plot of upper 30m averaged meridional current $\left(\mathrm{m} \mathrm{s}^{-1}\right)$ from ORAS4 and SODA with respect to OSCAR over the SMOC region during 1993-2009. This analysis suggests that the meridional surface currents of both ORAS4 as well as SODA display high correlation (0.89) with OSCAR. 
The error in meridional currents with respect to OSCAR for ORAS4 and SODA is 0.011 and $0.019 \mathrm{~m} \mathrm{~s}^{-1}$ respectively. In addition to the surface current observation, the subsurface meridional currents obtained from $A D C P$ are also considered for validation. Figure.1c shows the standard deviation of meridional currents from ORAS4, SODA and ADCP at the location $0^{\circ}, 90^{\circ} \mathrm{E}$ during the period November 2000 to December 2008. It is important to note that SODA and ORAS4 display a similar vertical structure of meridional current variability with depth relative to ADCP observations. The maximum deviation in meridional currents is confined between the depth of $60 \mathrm{~m}$ and $100 \mathrm{~m}$, which is underestimated by both SODA and ORAS4. The maximum deviation for ORAS4 is $\sim 0.07 \mathrm{~ms}^{-1}$ and for SODA is $\sim 0.075 \mathrm{~ms}^{-1}$ at $80 \mathrm{~m}$ depth. Below $120 \mathrm{~m}$, the deviation of meridional current reduced gradually, ORAS4 underestimated whereas SODA estimations are closer to the observed. Above analysis supports meridional currents in ORAS4 and SODA are consistent with satellite and in-situ observations and captured the variability of meridional currents. Since SODA dataset is available for longer period (during the last century 1871-2010) than ORAS4, motivation to use SODA dataset in further analysis to understand the variability in SMOC.

\section{Shallow Meridional Overturning Circulation Variability}

\subsection{Shallow Meridional Overturning Circulation}

Figure.2a displays latitudinal distribution of mean meridional transport (Sv) for upper 60m from SODA. It shows strong southward transport confined between equator and $20^{\circ} \mathrm{S}$ and peak of southward transport ( $\sim 7 \mathrm{~Sv}$ ) is observed between $5^{\circ} \mathrm{S}$ and $10^{\circ} \mathrm{S}$. South of it the strength of southward transport gradually decreases and changes its sign near $30^{\circ} \mathrm{S}$. Figure. $2 \mathrm{~b}$ shows the mean meridional overturning stream function and meridional and vertical currents manifest SMOC from SODA data. Highest magnitude of meridional overturning stream function (> 15Sv) is observed between the depth $50 \mathrm{~m}$ to $250 \mathrm{~m}$ centered over the latitude $8^{\circ} \mathrm{S}$. South of $15^{\circ} \mathrm{S}$ the vertical velocity is downward, denoting the region of mass convergence. Figure 2(c) shows the standard deviation of meridional overturning stream function for upper $60 \mathrm{~m}$, highest deviation ( $2.2 \mathrm{~Sv}$ ) is found at $10^{\circ} \mathrm{S}$. The standard deviation of meridional overturning stream function with depth (Fig. 2d) shows higher magnitude (> $2.5 \mathrm{~Sv}$ ) below $150 \mathrm{~m}$ within the latitude band $10^{\circ} \mathrm{S}$ to $20^{\circ} \mathrm{S}$ and 0 and $5^{\circ} \mathrm{N}$. Based on above analysis study regions from SMOC $\left(50^{\circ} \mathrm{E}\right.$ to $110^{\circ} \mathrm{E}$ and $8^{\circ} \mathrm{S}$ to $\left.15^{\circ} \mathrm{S}\right)$ and $\mathrm{CEC}\left(50^{\circ} \mathrm{E}\right.$ to $100^{\circ} \mathrm{E}$ and 0 to $\left.5^{\circ} \mathrm{N}\right)$ are identified (Fig. 2e). The mean of meridional volume and heat transport in the SMOC region is $-13.8 \mathrm{~Sv}$ and $-1.5 \mathrm{PW}$ respectively and corresponding standard deviation is $1.9 \mathrm{~Sv}$ and $0.22 \mathrm{PW}$ respectively. However, over the CEC region long term mean of meridional volume and heat transport is $-2 \mathrm{~Sv}$ and $-0.25 \mathrm{PW}$ and corresponding standard deviation is $1.3 \mathrm{~Sv}$ and $0.15 \mathrm{PW}$. Hence mean meridional volume/heat transport in CEC is smaller than SMOC region but variability is of almost same in magnitude.

4.2. Interannual variability in $\mathrm{SMOC}$ during last century

Figure 3 shows detrended meridional overturning stream function anomaly during the period 1871-2010 for upper $60 \mathrm{~m}$ (depth up to which annual mean meridional currents are southward) over SMOC, CEC and STC regions. Note that the variability in STC is estimated as the difference in stream function anomaly 
over SMOC and CEC. Figure 3(a) shows the time series of meridional overturning stream function anomaly, whenever it is higher than one standard deviation is considered strong SMOC year and anomalies lesser by one standard deviation is considered weak SMOC years. It has to be noted that the SMOC display strong interannual variability after 1940s. Based on the above analysis during the study period 15 strong and 12 weak events are identified (Table 1). Meridional stream function over the SMOC region and vertical velocity anomaly over the subduction zone displays significant positive correlation (0.56), indicates in phase relation between them. The variability in STC is found to be in phase (correlation is 0.48 ) with SMOC variability and CEC is found to be out of phase (Correlation is - 0.5 ), which is consistent with the Meng et al., (2020), reported using ORAS5 dataset during the period 19582016. The CEC (Fig. 3b) and STC (Fig. 3c) variability is also examined with vertical velocity anomaly over Somali-Oman coast and (Fig. 3b $43^{\circ} \mathrm{E}-48^{\circ} \mathrm{E}, 2^{\circ} \mathrm{N}-10^{\circ} \mathrm{N}$ ) Seychelles Thermocline Ridge (Fig. 3c, $50^{\circ} \mathrm{E}-$ $65^{\circ} \mathrm{E}, 3^{\circ} \mathrm{S}-12^{\circ} \mathrm{S}$ ) region. Vertical velocity anomaly over the Somali-Oman coast and Seychelles Thermocline Ridge displays negative correlation with the meridional stream function over the CEC and STC respectively.

Table 1

The strong and weak SMOC years identified based on the standard deviation of meridional overturning streamfunction over the SMOC region from SODA during the period 1871-2010.

\begin{tabular}{|c|c|}
\hline $\begin{array}{l}\text { Strong SMOC } \\
\text { years }\end{array}$ & $\begin{array}{l}\text { 1871, 1880, 1881, 1882, 1883, 1884, 1885, 1887, 1888, 1937, 1964, 2005, 2006, } \\
2008,2009\end{array}$ \\
\hline $\begin{array}{l}\text { Weak SMOC } \\
\text { years }\end{array}$ & 1903, 1912, 1913, 1914, 1923, 1941, 1943, 1949, 1950, 1959, 1962, 1991 \\
\hline
\end{tabular}

Table2: Strong and weak SMOC years identified based on standard deviation ( $0.87 \mathrm{~Sv}$ ) stream function over SMOC region from CTRL run during the period 1960-2009.

\begin{tabular}{|ll|}
\hline Strong years & $1969,1972,1975,1976,1982,1984,1988,1999,2000$ \\
\hline Weak years & $1963,1968,1973,1987,2003,2007$ \\
\hline
\end{tabular}

In order to study the spatial structure of SMOC during strong and weak SMOC years composite analysis is carried out. Figure 4(a-b) shows the depth-latitude plot of meridional overturning stream function anomaly and meridional and vertical currents anomaly for strong and weak years composite respectively. Figure 4(c) indicates the difference between stream function, meridional and vertical currents for strong composites to weak composite years. During the strong SMOC years (Fig. 4a) anomalous southward transport is reported in the upper ocean over $0^{\circ}$ to $20^{\circ} \mathrm{S}$. The stronger transport of about $-2.4 \mathrm{~Sv}$ is confined between the latitude band $2^{\circ} \mathrm{S}$ to $17^{\circ} \mathrm{S}$ below $50 \mathrm{~m}$, where standard deviation is maximum (Fig. 2b). For the weak years (Fig. 4b), the transport is anomalously northward with higher magnitude 
confined between $2^{\circ} \mathrm{S}$ to $18^{\circ} \mathrm{S}$. Vertical velocity over the subduction region during strong and weak SMOC years shows anomalous subduction and upwelling respectively. The difference from strong composite to that of weak suggests that the maximum changes occur between the latitudes $5^{\circ} \mathrm{S}$ and $15^{\circ} \mathrm{S}$, with peak near $10^{\circ} \mathrm{S}$. Also, large variation in vertical velocity is observed between $10^{\circ} \mathrm{S}$ and $20^{\circ} \mathrm{S}$. Figure $4(\mathrm{c}-\mathrm{d})$ shows spatial distribution of the vertical velocity anomaly composite for strong and weak SMOC years respectively. Negative (positive) anomaly manifest anomalous subduction (upwelling), and is mostly dominating over the region south of $10^{\circ} \mathrm{S}$ for strong (weak) SMOC years. The difference in the vertical velocity composite for strong to weak year (Fig. 4f) suggests that large changes occur between the latitudes $10^{\circ} \mathrm{S}$ and $20^{\circ} \mathrm{S}$ over South West Indian Ocean (SWIO).

\section{Heat Transport Variability Associated With Smoc}

Figure 5(a-b) shows composite of meridional heat transport anomaly forg strong and weak SMOC years. During strong SMOC years meridional heat transport anomaly is southward, denoting excess transport of heat to the south of the equator (Fig. 5a). The maximum transport is seen between the latitude $2^{\circ} \mathrm{S}$ and $17^{\circ} \mathrm{S}$ below $50 \mathrm{~m}$ with a magnitude of about $-0.25 \mathrm{PW}$. During weak SMOC years (Fig. $5 \mathrm{~b}$ ) structure of heat transport is opposite (northward) to that of strong SMOC years. Figure 5(c-d) shows composite of vertical profile of temperature anomaly over SWIO for strong and weak SMOC years from SODA and EN4 analysis during the period $1900-2010$. Temperature anomaly profile associated with strong SMOC years display negative anomaly at upper $250 \mathrm{~m}$ (Fig. $5 \mathrm{C}$ ), with maximum anomaly of $-0.7^{\circ} \mathrm{C}\left(-0.35^{\circ} \mathrm{C}\right)$ around the depth of $50 \mathrm{~m}$ in SODA (EN4) data. For the weak years the maximum positive anomaly of $0.4^{\circ} \mathrm{C}\left(\sim 0.3^{\circ} \mathrm{C}\right)$ is found around the $50 \mathrm{~m}(100 \mathrm{~m})$ in SODA (EN4) data (Fig. 5d). These analysis reveals that the strong SMOC years produced cooling and weak SMOC years produced warming in upper $200 \mathrm{~m}$ over the SWIO, which is also supported by the EN4 analysis data. Figure 5(e-f) shows the corresponding changes in the vertical profile of density, during the strong SMOC years increase in the upper ocean density and during the weak SMOC years reduction in the density in the upper ocean is found. This variation in the density is consistent with the upper ocean heat changes, thus circulation not only modifies the heat distribution but also modifies the vertical stability of the upper ocean, strong SMOC enhances the stability of the upper ocean and weak SMOC suppress the upper ocean stability in SWIO.

\section{Smoc Variability And Their Association With South West Indian Ocean Thermal Structure}

Figure 6 shows the composite of 200m Ocean Heat Content Anomaly (OHCA200) during strong and weak SMOC years from SODA (Fig.6a, b) during the period 1871-2010. To examine the consistency in the results obtained, the composites of OHCA200 during strong and weak years from two ocean analysis datasets, EN4 (Fig. 6c, d) and Ishi (Fig.6e, f) are estimated during the period 1959-2010, 1945-2010, respectively. It also shows correlation and regression analysis between OHCA200 and SMOC variability during respective periods. OHCA200 during strong SMOC years (Fig. 6a) display negative anomalies over the SWIO, off Somali coast, whereas positive anomalies in south of $20^{\circ} \mathrm{S}$, south eastern Indian Ocean, 
and strong positive anomaly in BoB, which is other way in the EN4 and Ishi analysis (Fig.6c and e). Weak SMOC years composite shows positive anomalies in SWIO and off Somali coast while rest of the region displayed negative OHCA200(Fig. 6b). It is important to note that relative magnitude of OHCA200 are lesser in Ishi than SODA and EN4 (Fig. 6d and f). The contour in the Fig. 6(a, c, and e) represents the correlation between OHCA200 and SMOC variability index during respective periods. The dot denotes the correlation above $90 \%$ confidence level. In addition, inter-correlation for OHCA200 variability among data product SODA, EN4 and Ishi for South-West Indian Ocean is found greater than 0.7. This analysis reveals that the SMOC variability influence the SWIO heat content, supported by the EN4 and Ishi data and displayed significant positive correlation with $90 \%$ confidence level in all the three data sets, however OHCA200 signal for other regions failed to have consensus with all the three data products.

Figure 7(a) shows time series of meridional overturning stream function anomaly and OHCA200 for the SWIO. The correlation between them for the study period is 0.32 , which supports in phase variation. Figure 7(b) shows time series of upper ocean current divergence and thremocline depth anomaly and Figure 7(c) shows time series of upper ocean current divergence and OHCA200 for the SWIO, they show negative correlation. This indicates that variation in thermocline depth and OHCA200 are out of phase with the divergence of the upper ocean circulation. Figure 7(d) shows the evolution of OHCA200 with the SLA over the SWIO. Analysis reveals that OHCA200 and SLA displayed coherent variability in the SWIO with correlation 0.83 for SODA. The tide gauge data for the shorter period (1958-1972) from the Madagascar station NOSY-BE $\left(13.4^{\circ} \mathrm{S}, 48.3^{\circ} \mathrm{E}\right)$ also displayed a coherent sea level variation and OHCA200 with 0.72 correlation coefficient supporting the results obtained from SODA. In addition, correlation analysis for sea level data during the recent period from satellite with the OHCA200 for SWIO also confirmed in phase relation with correlation coefficient 0.6 . Above analysis confirms that during the weak SMOC years, heat transport gets converged in the SWIO, which leads deepening of thermocline and increase of OHCA200 and sea level rise and vice versa during the strong SMOC years.

\section{Mechanism Responsible For Interannual Variability In Smoc}

Figure 8 shows time series of upper $60 \mathrm{~m}$ Meridional Heat Transport (MHT) anomaly and zonal wind stress anomaly over the SMOC region (Fig. 8a), time series of SOI and zonal wind stress anomaly over the SMOC region (Fig. 8b) and time series of MHT and SOI (Fig.8c) during study period (1871-2010). Time series of zonal wind stress anomaly and MHT shows coherent variation between them with correlation coefficient 0.82 . This suggests that during the study period stronger SMOC are associated with the anomalous easterlies and weaker SMOC are associated with anomalous westerlies over the SMOC region. However, MHT and zonal wind stress displayed negative correlation coefficient $(-0.33$ and 0.-31) with the SOI (Fig. 8b and c), indicating that the negative SOI (i.e., El Niño condition) favors below normal easterly wind stress in the south Indian Ocean and corresponding southward heat transport is less than its normal and vice versa when SOI is positive. This analysis manifest that the MHT variability is driven by the zonal wind anomaly which is to some extent is forced by the ENSO variability. Hence the strong years are associated with La Niña and weak SMOC years are associated with El Niño. Hence the 
heat transport and OHCA200 in the SWIO is driven by atmospheric pathway connected with the eastern Pacific temperature anomaly. Figure 9( $a$ and $b$ ) shows the composite of zonal wind stress anomalies during strong and weak SMOC years, it further confirms that strong SMOC years are associated with stronger easterly wind anomaly with magnitude of 1 to $1.5 \mathrm{~m} / \mathrm{s}$ over the SIO $\left(5^{\circ} \mathrm{S}\right.$ to $\left.25^{\circ} \mathrm{S}\right)$ and weak SMOC years are associated with westerly wind anomaly with same magnitude. It is clear from the Fig. 8c, that the changes in local surface wind circulation driving the variability in SMOC (Fig. 9a and b) have association with ENSO. It would be also important to explore how ENSO conditions over central and eastern equatorial Pacific alter the local surface wind circulation. Figure 10 ( $a$ and $b$ ) indicates the composite of the velocity potential (shaded, $10^{6} \mathrm{~m}^{2} \mathrm{~s}^{-1}$ ) and divergent wind anomalies (vector, $\mathrm{ms}^{-1}$ ) at 200hpa during the strong and weak SMOC years. During strong SMOC years, strong anomalous upper level convergence over central equatorial Pacific and divergence over central Indian Ocean is observed. The anomalous velocity potential indicates that the center of maximum divergence component of the wind is situated at central Indian Ocean. Also, the center of maximum convergent component is extended from central to eastern equatorial Pacific denoting La Niña type conditions. Similar pattern in upper level divergence and velocity potential has been reported in previous studies during La Niña (e.g., Raj Deepak et al., 2019). It has to be noted that the pattern of velocity potential and upper level wind divergence reverse during weak SMOC years with respect to strong years (Fig. 10b), indicating El Niño type conditions in eastern Pacific. During the weak SMOC years, the center of anomalous convergence is situated at eastern equatorial Indian Ocean. Hence the analysis suggests that the La Niña (El Niño) type conditions persists over equatorial Pacific enhances (weakens) the upper level wind divergence over Indian Ocean supporting variation in surface winds observed in Fig. 9.

In order to confirm the role of the wind variability to the SWIO heat content, sea level and thermocline variability, ocean model based experiments, is carried out for the period 1962-2009. In the CTRL experiment ocean model is forced by interannually varying forcing over the global ocean. Whereas in IOSMOC experiments only interannually wind forcing allowed over Indian Ocean and rest of the forcing fields are long term mean over the global ocean. It is important to note that the strong and weak years for the model study period are identified based on standard deviation of annual mean meridional overturning stream function in the CTRL (Table2). The composite of meridional overturning stream function anomaly and anomalous SMOC for strong and weak years from CTRL is shown in Fig.11 (a-b). Negative(positive) transport anomaly, with magnitude more than 2Sv below $150 \mathrm{~m}$ depth, is reproduced by the model during strong (weak) years in CTRL. In comparison with the spatial pattern of anomalous SMOC obtained from SODA (Fig.4a and b) CTRL simulation underestimates meridional transport anomalies however it captured pattern of transport anomalies corresponding to strong and weak SMOC year composite. It is also important to note that CTRL could simulate anomalous downwelling (upwelling) around $10^{\circ} \mathrm{S}$ during strong (weak) SMOC years. Above analysis supports that though CTRL underestimates the magnitude of the meridional anomaly strength but reproduces a pattern of meridional overturning stream function anomaly consistent with SODA. Figure 11 (c-d) shows composite of meridional overturning stream function anomaly and anomalous SMOC for strong and weak years from IOSMOC. The strong and weak SMOC pattern and vertical motions are well captured, though magnitudes are underestimated. This

Page $11 / 29$ 
analysis reveals that the change in SMOC largely depend on the interannual variation of the local wind over SIO. Figure 12 shows composite of OHCA200 and SLA for strong (Fig. 12a, c) and weak (Fig.12 b, d) years from CTRL and IOSMOC experiments respectively. CTRL displays negative anomaly of OHCA200 in the SWIO for strong year composite and positive anomaly of OHCA200 for weak SMOC years (Fig.12ab). North BoB and south east Indian Ocean shows weak OHCA200 and opposite to SWIO, however Arabian Sea does not show any change during these years. Corresponding changes in the SLA are also reported in the SWIO, for negative OHCA200, SLA of the order of $-3 \mathrm{~cm}$ and for positive OHCA200, SLA of the order of $4 \mathrm{~cm}$ is found. Similar analysis is carried out for IOSMOC, which reproduced the OHCA200 and SLA spatial pattern like in CTRL for the strong and weak SMOC years composites. Analysis supports that the OHCA200 and SLA reported for the strong and weak SMOC years are driven by the wind forcing and role of Pacific variability through oceanic pathway is negligible.

\section{Summary And Conclusion}

The variability of Indian Ocean SMOC during the last century (1871-2010) is studied using SODA reanalysis data. The magnitude of the annual mean meridional overturning stream function over the study region $\left(8.5^{\circ} \mathrm{S}-15^{\circ} \mathrm{S}, 50^{\circ} \mathrm{E}-110^{\circ} \mathrm{E}\right)$ is considered as $\mathrm{SMOC}$ strength. The validation of upper ocean meridional currents from SODA with respect to that of OSCAR as well as ORAS4 confirmed that SODA data is consistent with observation and capture the observed variability over the study region. Strong (weak) SMOC years are identified based on the mean meridional overturning stream function anomaly greater(less) than its standard deviation. The composite analysis of stream function anomaly for strong (weak) years reveals a maximum (minimum) transport ( 2.5Sv) between the latitude band $5^{\circ} \mathrm{S}$ and $15^{\circ} \mathrm{S}$ within the first $500 \mathrm{~m}$. For strong and weak SMOC years, the heat transport ( 0.25 PW) associated with SMOC is also displaying the peak between the same latitude. The impact of meridional heat transport variability associated with SMOC to temperature, upper ocean stability, upper $200 \mathrm{~m}$ Ocean Heat Content, thermocline depth and sea level is also examined. This analysis reveals that strong SMOC leads negative anomaly in upper ocean temperature, heat content, sea level and thermocline depth in the SWIO and vice versa for weak SMOC. Correlation analysis of meridional overturning stream function anomaly with the oceanic heat content during the study confirms negative correlation over the SWIO with the confidence level of $90 \%$. This pattern of correlation and heat content anomaly for the SWIO is also supported by the EN4 and Ishi independent ocean analysis data. In addition, analysis with the tide gauge sea level data from Madagascar station NOSY-BE $\left(13.4^{\circ} \mathrm{S}, 48.3^{\circ} \mathrm{E}\right)$ with OHCA200 as well as SLA data from satellite observation shows significant correlation, confirms that SMOC variability modulates SWIO upper ocean heat content and sea level. SMOC, zonal wind south of equator in Indian Ocean and SOI in Pacific shows coherent evolution indicating the influence of eastern Pacific temperature (ENSO) variability on SMOC variability. The upper level divergence and velocity potential over Indian Ocean are consistent with the surface circulation, indicating Pacific influence of variability though atmospheric bridge. To confirmed the role of atmospheric path way contributing to the SMOC variability, ocean model-based CTRL and sensitivity experiment (IOSMOC) is carried out, in which only Indian ocean is forced with interannually varying wind fields and the climatological winds are retained over rest of the domain for forcing. The

Page $12 / 29$ 
results from the IOSMOC experiment reveals that the strong and weak events identified in SMOC are not associated with remote forcing from Pacific through oceanic pathway, but are solely due to local wind variability response to ENSO.

\section{Declarations}

\section{Acknwoledgment}

\section{Funding Statement}

No funding.

\section{Author information}

\section{Affiliations}

Savitribhai Phule Pune University, Pune, India

Rahul Pai

Indian Institute of Tropical Meteorology, Ministry of Earth Sciences, Pune, India

Rahul U. Pai, Anant Parekh, Jasti S. Chowdary, C. Gnanaseelan

\section{Author's Contribution}

AP and RUP designed, conceptualized the study. The generation of plots and code development is done by RUP. Model experiments and analysis are carried out by RUP under supervision of AP. RUP, AP, JSC and CG have contributed to the discussions as well as in manuscript writing

\section{Corresponding author}

Correspondence to Rahul Pai

\section{Availability of data and material}

The details of publicly available datasets are mentioned in Section2. The model outputs used in this study are not publicly available and can be accessed from the corresponding author upon reasonable request.

\section{Code availability}

All of the figures in the study are prepared using free visualization tool PyFerret.

\section{Ethics approval}


The manuscript has not been submitted/published elsewhere previously.

\section{Conflict of interest}

The authors declare that there is no conflict of interest.

\section{Consent to participate}

Not applicable.

\section{Consent for publication}

Not applicable

\section{References}

Balmaseda, MA, Mogensen K, Weaver AT (2013) Evaluation of the ECMWF ocean reanalysis system ORAS4. Quarterly Journal of Royal Meteorological Society, 139(674), 11321161. https://doi.org/10.1002/qj.2063.

Balmaseda MA, Hernandez F, Storto A, Palmer MD, Alves O, Shi L, Smith GC, Toyoda T, Valdivieso M, Barnier B, Behringer D (2015) The ocean reanalyses intercomparison project (ORA-IP). Journal of Operational Oceanography, 8(sup1), pp. s80-s97. https://doi.org/10.1080/1755876X.2015.1022329.

Bryan K, Lewis LJ (1979) A water mass model of the world ocean. Journal of Geophysical Research 84, 2503-2517.

Carton J, Giese B (2008) Reanalysis of ocean climate using Simple Ocean Data Assimilation (SODA). Mon Weather Rev 136:2999-3017. https://doi.org/10.1175/2007MWR1978.1.

Chirokova G, Webster PJ (2006) Interannual Variability of Indian Ocean Heat Transport Journal of Climate, 19(6), 1013-1031. https://doi.org/10.1175/JCLI3676.1.

Ducet N, Le Traon PY, Reverdin G (2000) Global high-resolution mapping of ocean circulation from TOPEX/Poseidon and ERS-1 and -2. Journal of Geophysical Research, 105(C8), 1947719498. https://doi.org/10.1029/2000JC900063.

Ganachaud A, Wunsch C (2003) Large scale ocean heat and freshwater transports during the World Ocean Circulation Experiment. Journal of Climate, 16, 696-705. https://doi.org/10.1175/15200442(2003)016\%3C0696:LSOHAF\%3E2.0.CO;2.

Garternicht U, Schott FA (1997) Heat fluxes of the Indian Ocean from a global eddy-resolving model. J Geophys Res Oceans, 102, 21 147-21 159. https://doi.org/10.1029/97JC01585. 
Giese BS, Ray S (2011) El Niño variability in simple ocean data assimilation (SODA), 1871-2008. J Geophys Res Oceans. https://doi.org/10.1029/2010JC006695.

Good SA, Martin MJ, Rayner NA (2013) EN4: Quality controlled ocean temperature and salinity profiles and monthly objective analyses with uncertainty estimates. J Geophys Res Oceans, 118(12), pp.67046716. https://doi.org/10.1002/2013JC009067.

Griffies SM, Winton M, Donner LJ, Downes SM, Farneti R, Gnanadesikan A, Horowitz LW, Hurlin WJ, Lee HC, Liang Z, Palter JB, Samuels BL, Wittenberg AT, Wyman BL, Yin J, Zadeh NT (2011) GFDL's CM3 coupled climate model: Characteristics of the ocean and sea ice simulations. Journal of Climate 24, 3520-3544. https://doi.org/10.1175/2011JCLI3964.1.

Griffies SM (2012) Elements of the modular ocean model (MOM). GFDL Ocean Group Tech. Rep, 7, p.620.

Han W, Meehl GA, Hu A et al. (2014) Intensification of decadal and multi-decadal sea level variability in the western tropical Pacific during recent decades. Clim Dyn 43, 1357-

1379. https://doi.org/10.1007/s00382-013-1951-1.

Horii T, Mizuno K, Nagura M, Miyama T, Ando K (2013) Seasonal and interannual variation in the crossequatorial meridional currents observed in the eastern Indian Ocean. J Geophys Res Oceans, 118(12), pp.6658-6671. https://doi.org/10.1002/2013JC00929.

Ishii M, Kimoto M, Kachi M (2003) Historical Ocean Subsurface Temperature Analysis with Error Estimates. Monthly Weather Review, 131(1), 51-

73. https://doi.org//10.1175/15200493(2003)131<0051:HOSTAW>2.0.C0;2

Kanzow A, Cunningham WE, Jhons JJ, Hirschi J, Marotzke MO, Banringer CS, Meinin MP, Chidichimo, Atkinson LM, Beal HL, Bryden (2009) Seasonal Variability of the Atlantic Meridional Overturning Circulation at 26.58N. Jounal of Climate, https://doi.org/10.1175/2010JCLI3389.1.

Karmakar A, Parekh A, Chowdary JS et al. (2018) Inter comparison of Tropical Indian Ocean features in different ocean reanalysis products. Clim Dyn 51, 119-141. https://doi.org/10.1007/s00382-017-3910-8.

Large W, McWilliams J, Doney S (1994) Oceanic vertical mixing: a review and a model with a nonlocal boundary layer parameterization. Reviews of Geophysics 32, 363403. https://doi.org/10.1029/94RG01872.

Large W, Yeager SG (2004) Diurnal to decadal global forcing for ocean and sea-ice models: the data sets and flux climatologies. Tech. Rep. NCAR/TN-460+STR, National Center for Atmospheric Research.

Large WG, Yeager SG (2009) The global climatology of an interannually varying air-sea flux data set. Climate dynamics, 33(2-3), pp.341-364. https://doi.org/10.1007/s00382-008-0441-3. 
Lee SK, Park W, Baringer, M et al. (2015) Pacific origin of the abrupt increase in Indian Ocean heat content during the warming hiatus. Nature Geosci 8, 445-449. https://doi.org/10.1038/ngeo2438.

Lee T, Marotzke J (1997) Seasonal cycles of meridional overturning and heat transport of the Indian Ocean. Journal of Physical Oceanography 28, 923-943. https://doi.org/10.1175/15200485(1998)028\%3C0923:SCOMOA\%3E2.0.CO;2.

Lee T (2004) Decadal weakening of shallow overturning circulation in the South Indian Ocean, American Geophysical Union, Issue 22. https://doi.org/10.1029/2004GL020884.

Levitus S, Boyer T, Conkright M, Johnson D, O'Brien T, Antonov, Stephens C, Gelfeld, R (1998) World Ocean Database Atlas NESDIS 18, NOAA

Madec G (2008) NEMO reference manual, ocean dynamics component: NEMO-OPA. Preliminary version. Note du Pole de modélisation, Institut Pierre-Simon Laplace (IPSL), France, 27, pp.1288-161.

Masumoto Y, Hase H, Kuroda Y, Matsuura H, Takeuchi H (2005) Intraseasonal variability in the upper layer currents observed in the eastern equatorial Indian Ocean, Geophys Res Lett, 32, L02607. https://doi.org/10.1029/2004GL021896.

McPhaden M, Zhang D (2002) Slowdown of the meridional overturning circulation in the upper Pacific Ocean. Nature 415, 603-608. https://doi.org/10.1038/415603a.

McPhaden MJ, Zhang D (2004) Pacific Ocean circulation rebounds. Geophysical Research Letters, 31(18), L18301. https://doi.org/10.1029/2004GL020727.

Meng L, Zhuang W, Zhang W, Yan C, Yan XH (2020) Variability of the shallow overturning circulation in the Indian Ocean. J Geophys Res Oceans, 125, e2019JC015651. https://doi.org/10.1029/2019JC015651

Miyama T, McCreary Jr JP, Jensen TG, Loschnigg J, Godfrey JS, Ishida A (2003) Structure and dynamics of the Indian-Ocean cross-equatorial cell, Deep Sea Res.,50,2023-2047. https://doi.org/10.1016/S09670645(03)00044-4.

Mohapatra S, Gnanaseelan C, Deepa JS (2020) Multidecadal to decadal variability in the equatorial Indian Ocean subsurface temperature and the forcing mechanisms. Clim Dyn 54, 3475-3487. https://doi.org/10.1007/s00382-020-05185-7.

Motoki N, McPhaden MJ (2017) The shallow overturning circulation in the Indian Ocean, AMS, DOI: 10.1175/JPO-D-17-0127.1

Raj Deepak SN, Chowdary JS, Dandi AR et al. (2019) Impact of multiyear La Niña events on the South and East Asian summer monsoon rainfall in observations and CMIP5 models. Clim Dyn 52, 69897011. https://doi.org/10.1007/s00382-018-4561-0. 
Ruijin H, Qinyu L, Qi W et al. (2005) The shallow meridional overturning circulation in the northern Indian Ocean and its interannual variability. Adv. Atmos. Sci. 22, 220229. https://doi.org/10.1007/BF02918511.

Schott FA, Dengler M, Schoenefeldt R (2002) The shallow overturning circulation of the Indian Ocean,Prog Oceanogr, 53,57-103. https://doi.org/10.1016/S0079-6611(02)00039-3.

Schott FA, McCreary J, Johnson G (2004) Shallow overturning circulations of the tropical-subtropical oceans. In: Wang CSX, Carton J (eds) Earth's climate: the ocean-atmosphere interaction. American Geophysical Union, Washington, D.C. https://doi.org/10.1029/147GM15.

Schoenefeldt R, Schott FA (2006) Decadal variability of the Indian Ocean cross-equatorial exchange in SODA. Geophys. Res. Lett., 33, L08602, doi:10.1029/2006GL025891.

Sikhakolli R, Sharma R, Basu S, Gohil BS, Sarkar A, Prasad KVSR (2013) Evaluation of OSCAR ocean surface current product in the tropical Indian Ocean using in-situ data. Journal of Earth System Science, 122(1), 187-199.

Trenary LL, Han W (2013) Local and remote forcing of decadal sea level and thermocline depth variability in the south Indian Ocean. J Geophys Res Oceans, 118(1), pp.381-

398. https://doi.org/10.1029/2012JC008317.

Ummenhofer CC, Schwarzkopf FU, Meyers G, Behrens E, Biastoch A, Böning CW (2013) Pacific Ocean contribution to the asymmetry in eastern Indian Ocean variability. J Clim 26:1152-

1171. https://doi.org/10.1175/JCLI-D-11-00673.1.

Unnikrishnan AS, Nidheesh AG, Lengaigne M (2015) Sea level rise trends off the Indian coasts during the last two decades. Curr Sci 108(5): 966-971

Volkov DL, Fu LL, Lee T (2010) Mechanisms of the meridional heat transport in the Southern Ocean. Ocean Dynamics 60, 791-801. https://doi.org/10.1007/s10236-010-0288-0.

Volkov D, Lee S, Gordon A, Rudko M (2020) Unprecedented reduction and quick recovery of the South Indian Ocean heat content and sea level in 2014-2018. Sci Adv 6(36):

eabc1151. https://doi.org/10.1126/sciadv.abc1151.

Wang Y, McPhaden MJ (2017) Seasonal cycle of cross-equatorial flow in the central Indian Ocean. J Geophys Res Oceans, 122(5), 3817- 3827. https://doi.org/10.1002/2016jc012537.

Zhang D, McPhaden M (2006) Decadal variability of the shallow Pacific meridional overturning circulation: relation to tropical sea surface temperatures in observations and climate change models. Ocean Model 15(3):250-273. https://doi.org/10.1016/j.ocemod.2005.12.005. 
Figures
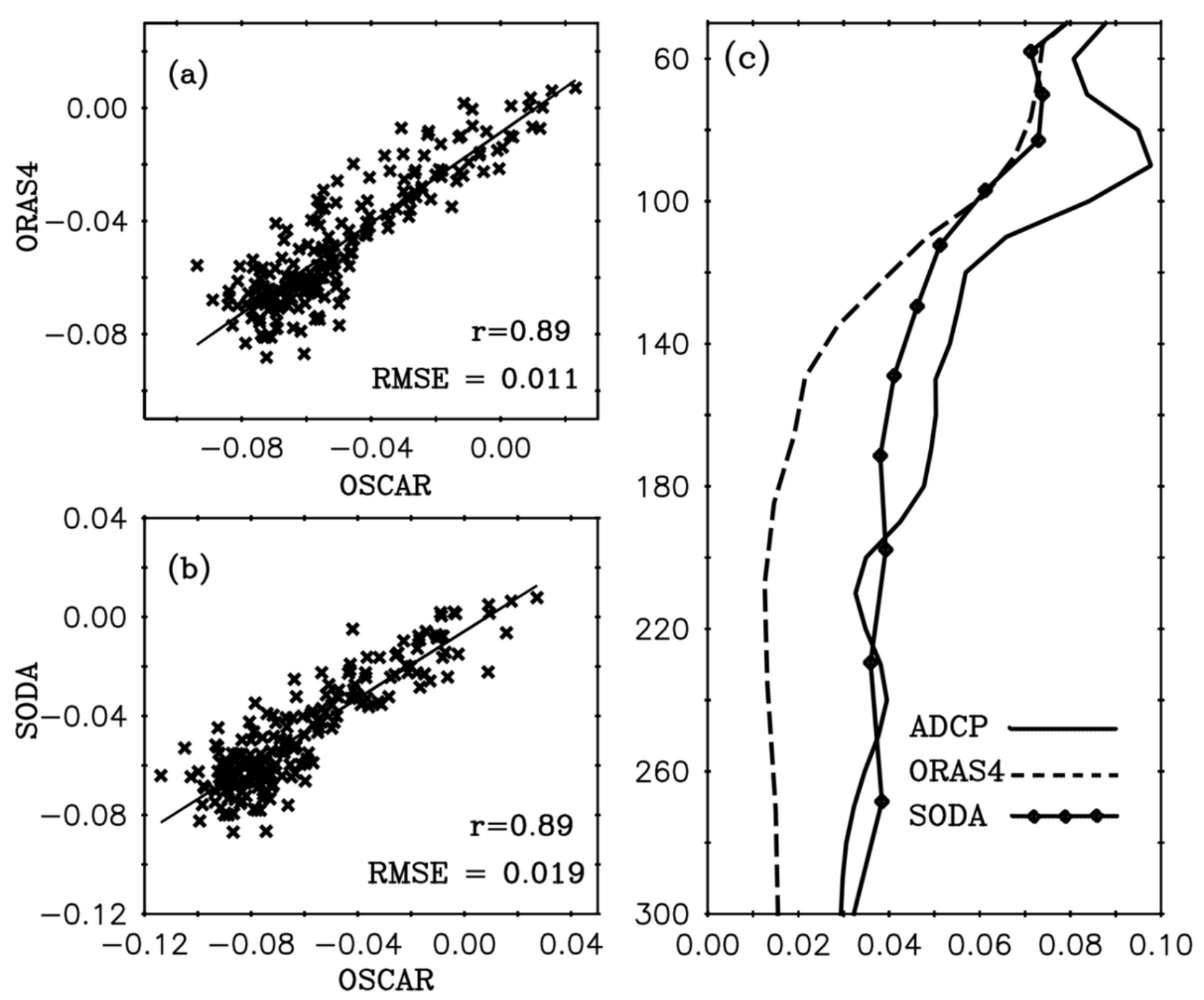

Figure 1

Scatter plot of upper 30m averaged meridional current ( $\mathrm{m} \mathrm{s}-1$ ) from (a) ORAS4 and (b) SODA with respect to OSCAR over SMOC region (8.5oS-15oS, 50oE-110oE) during the period 1993-2009. (c) Standard deviation profile of meridional current from ORAS4 and SODA and ADCP at the location 0o, 90oE from November 2000 to December 2008. 


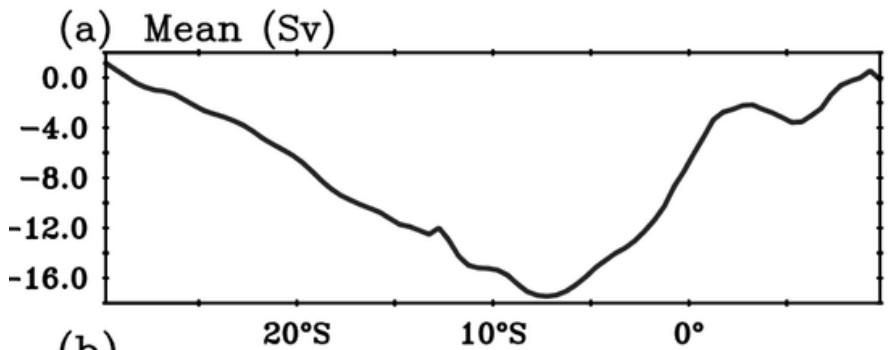

(b)

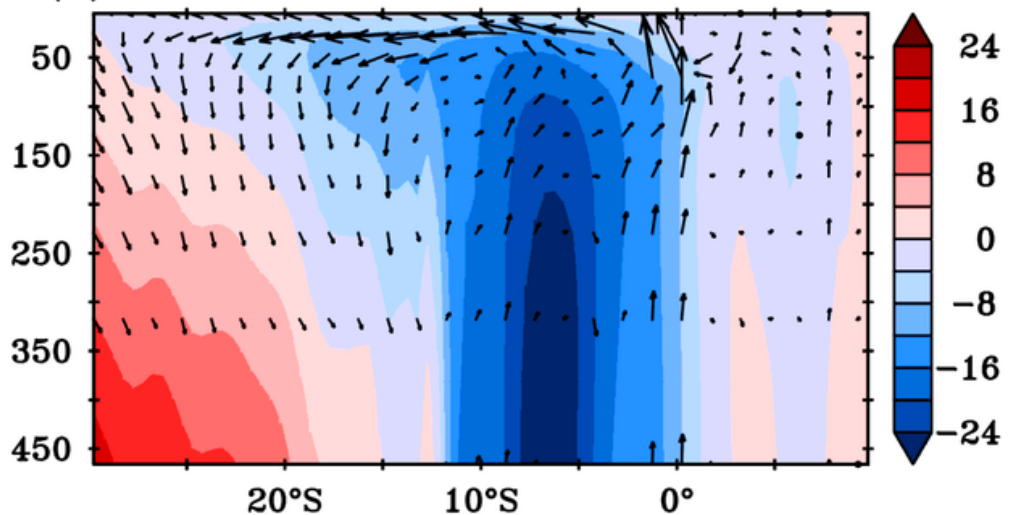

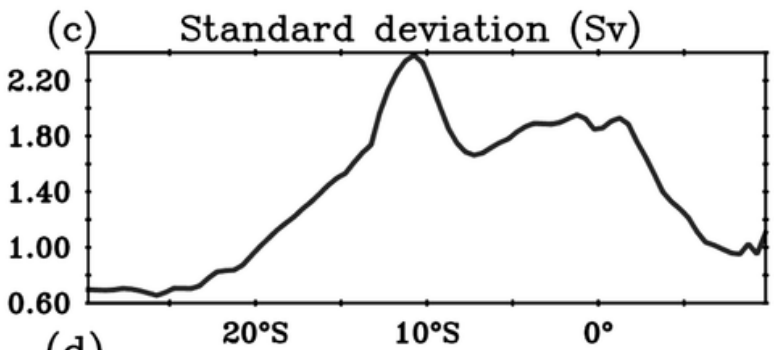

(d)

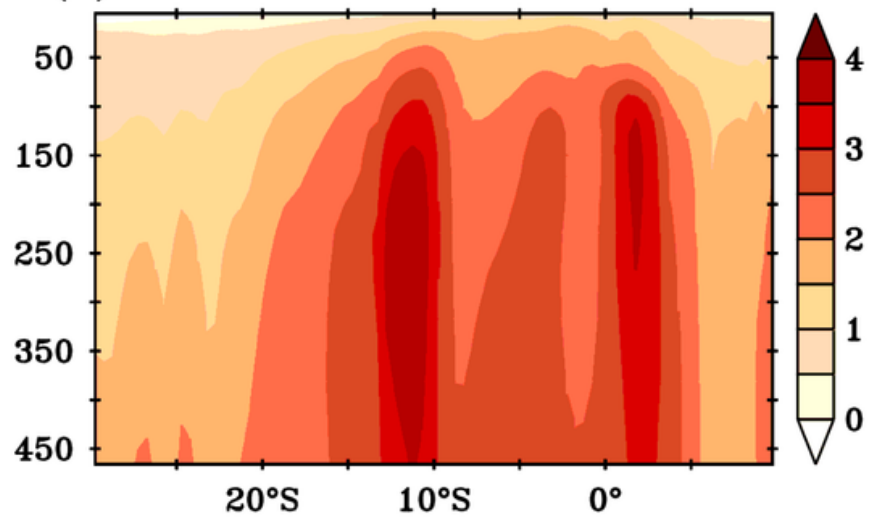

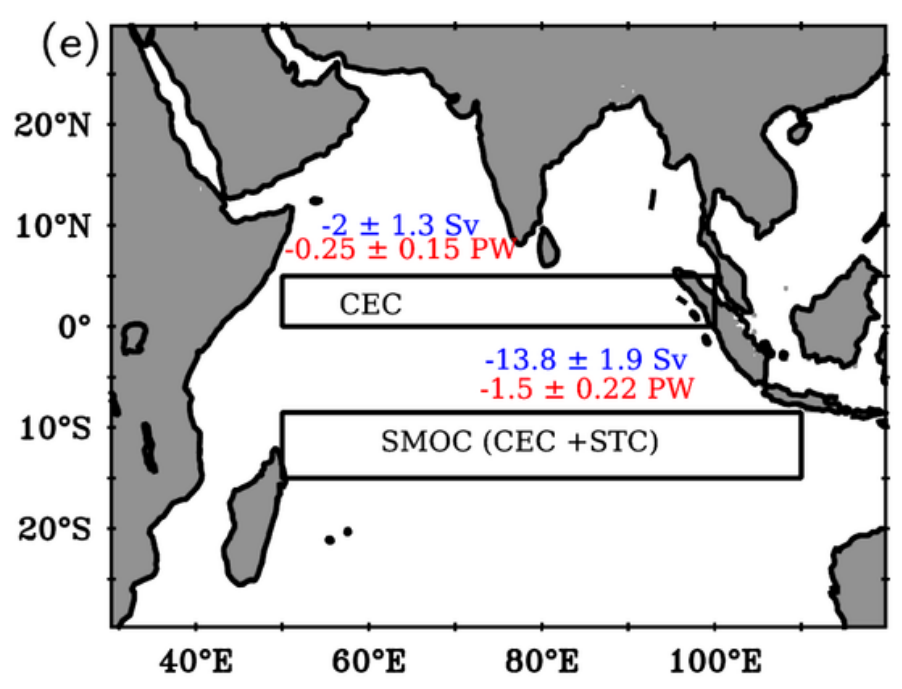

Figure 2

(a) Mean meridional transport in upper 60m from SODA during the period 1871-2010. (b) Annual mean meridional overturning stream function ( $\mathrm{Sv}$, shaded) and currents (ms-1, vector). Interannual standard deviation of stream function at upper $60 \mathrm{~m}$ (c) and its depth-latitude section from SODA (d). (e) Schematic of study regions considered based on standard deviation in (c). The box averaged upper $60 \mathrm{~m}$ mean meridional transport (Sv) and heat (PW) transports and their standard deviation are also given. 

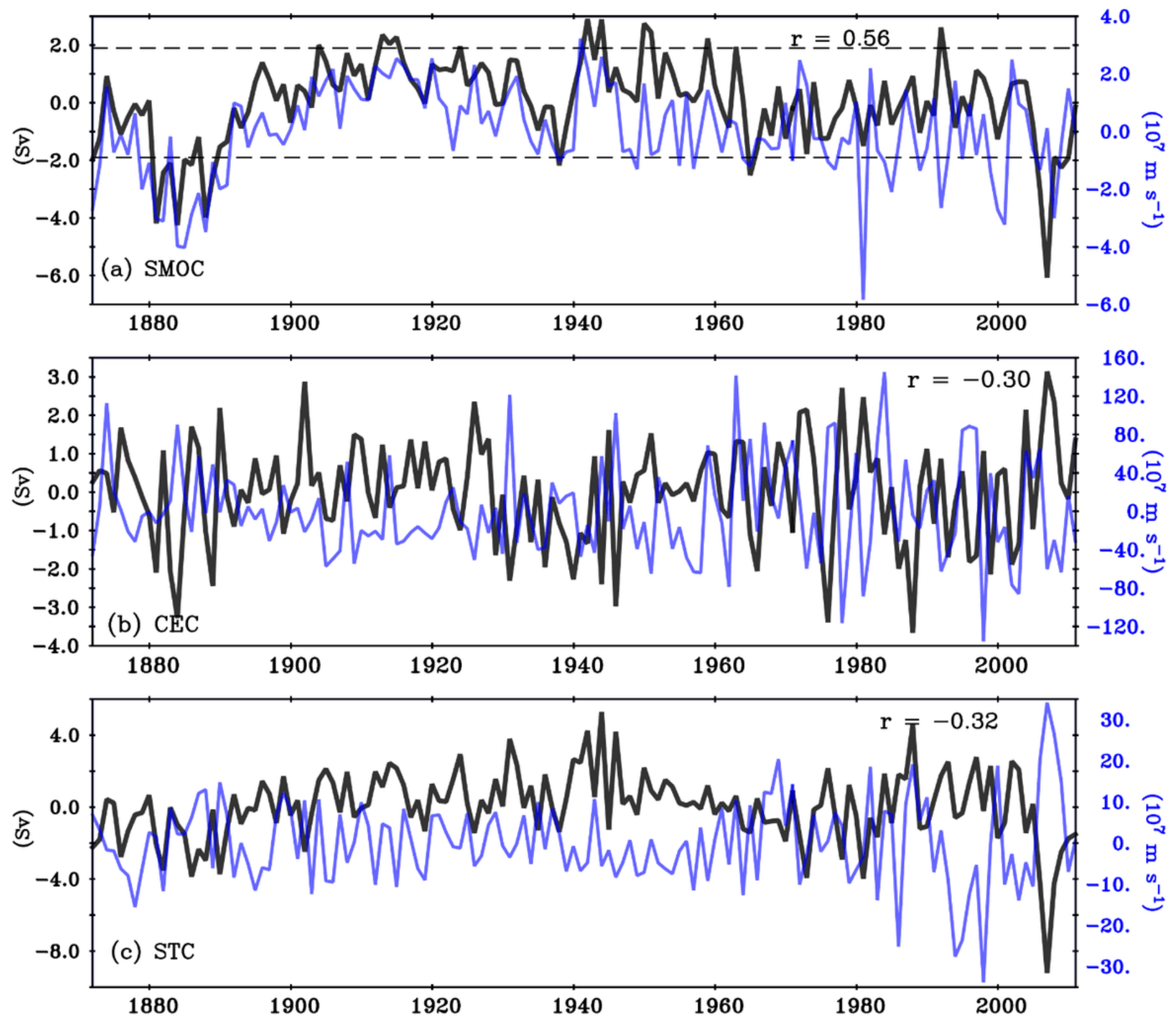

Figure 3

Time series of detrended meridional overturning stream function anomaly (black) at upper $60 \mathrm{~m}$ for (a) SMOC, (b) CEC and (c) STC and vertical velocity anomaly (blue) over (a) subduction zone (50oE-100oE, 20oS-30oS) (b) Somali-Oman coast and (43oE-48oE,2oN-10oN) (c) Seychelles Thermocline Ridge (50oE$65 \mathrm{oE}, 3 \mathrm{OS}-12 \mathrm{oS}$ ) region from SODAv2.2.4. The dashed line denotes the standard deviation 1.9Sv. 

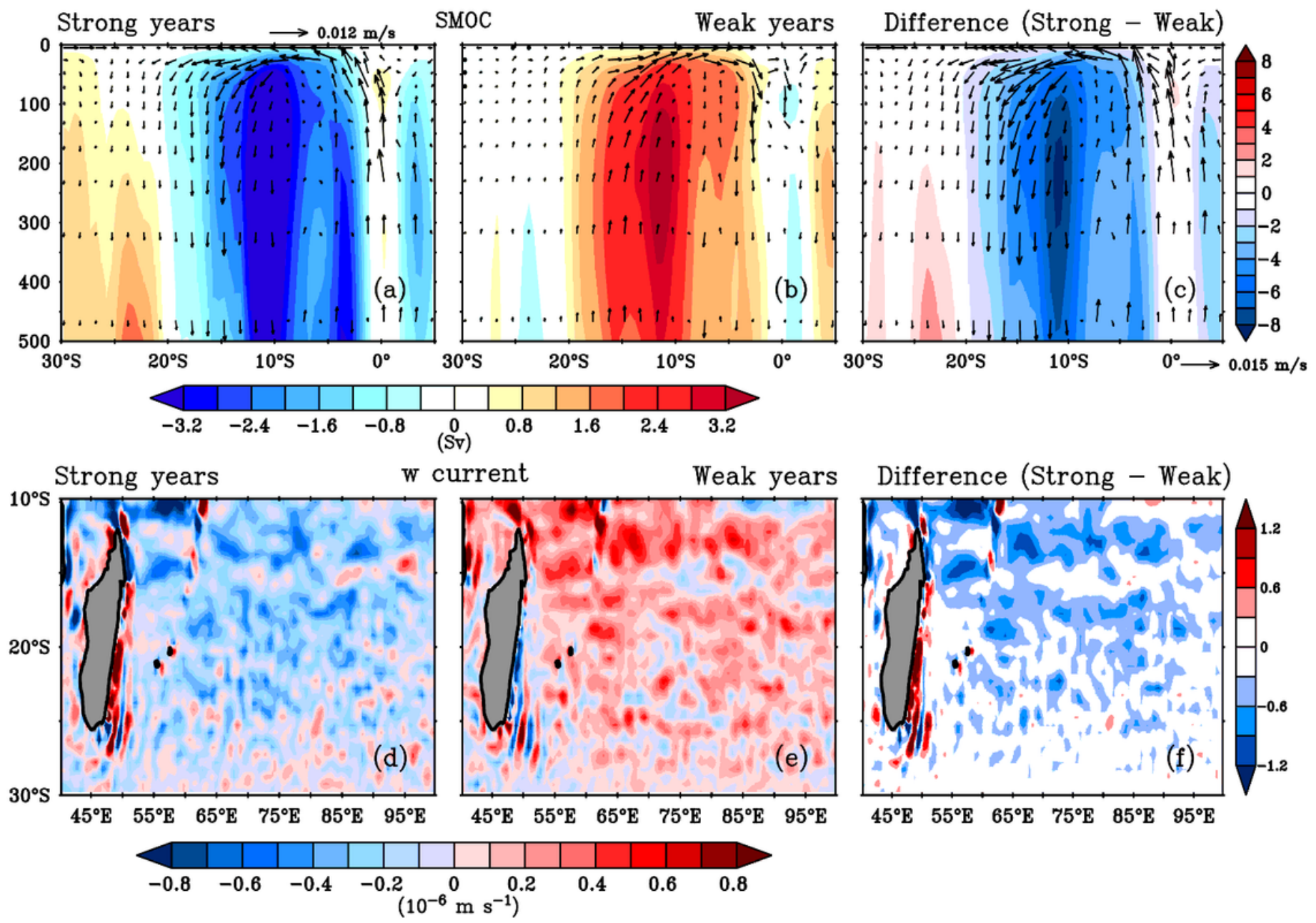

Figure 4

Depth-latitude plot for composite of meridional overturning stream function anomaly (shaded, Sv) and anomalous meridional and vertical currents (ms-1, vectors) for (a) strong and (b) weak SMOC years. Please note that the vertical velocity is multiplied by a factor of 10-4. Anomalous vertical velocity (10-6 ms-1) at 75m during (c) strong and (d) weak SMOC years during the period 1871-2010 is also given. The difference between strong and weak years (c and $f$ ) is also shown. 

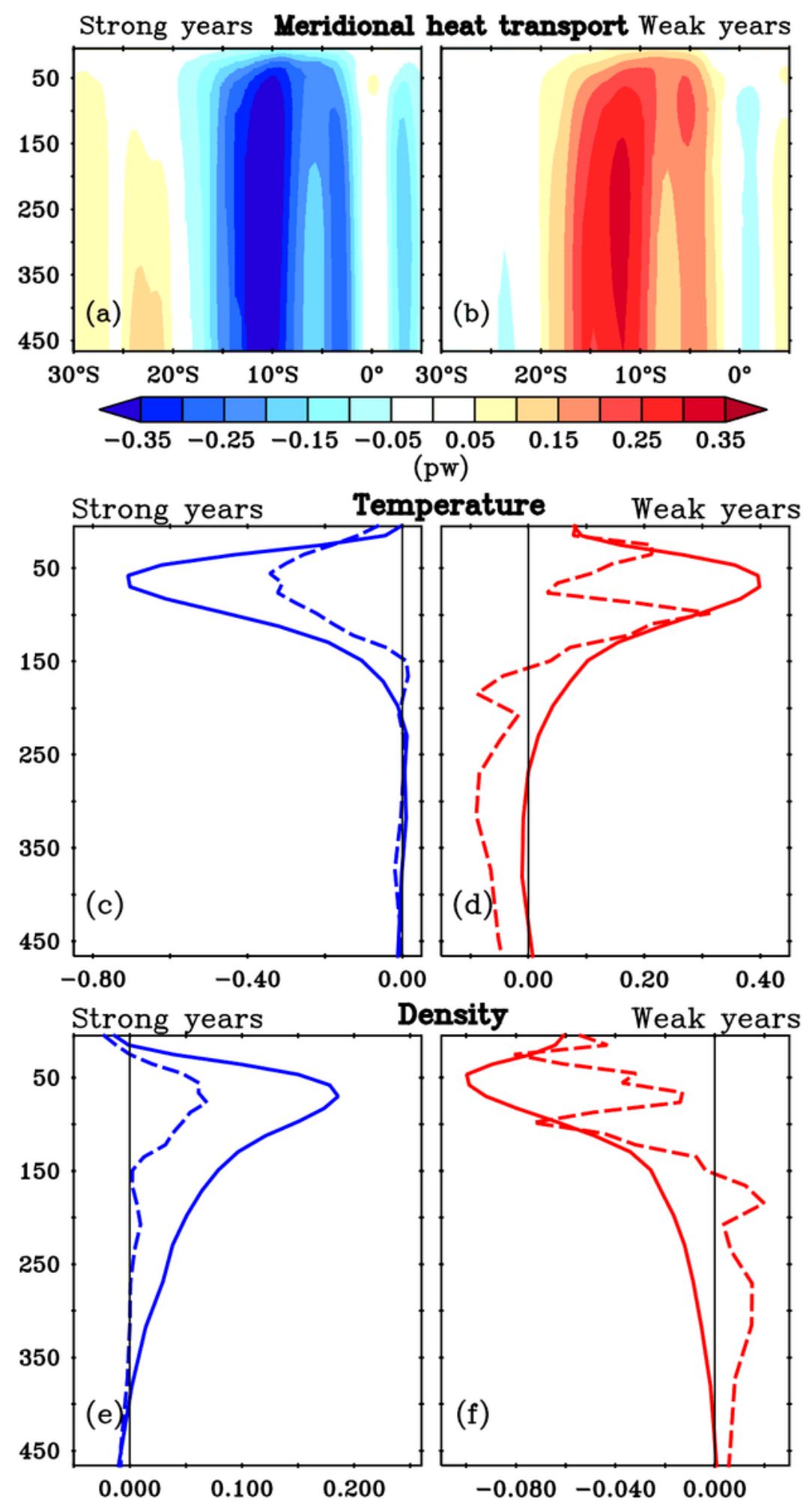

Figure 5

Composite of meridional heat transport anomaly (PW) during (a) strong and (b) weak SMOC years from SODAv2.2.4 dataset during the period 1871-2010. Vertical profile of temperature (oC) (c, d) and density (Kg m-3) (e, f) anomalies over south-western box (45oE-65oE, 5oS-15oS) during strong and weak SMOC years obtained from SODA (solid line) and EN4 (dashed line) datasets during the period 1900-2010. 
(a) Strong SMOC years

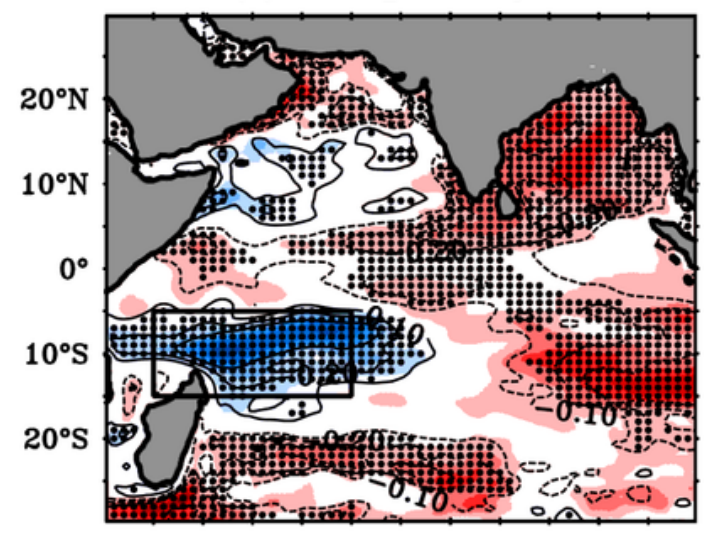

(c) Strong SMOC years

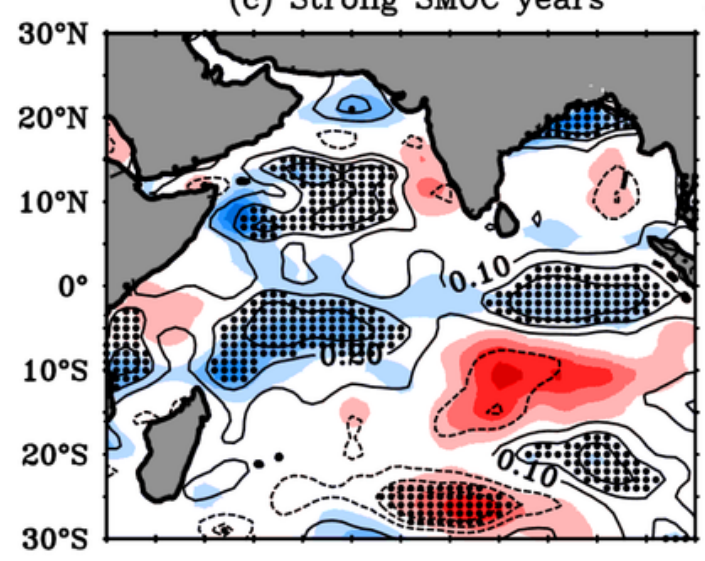

(e) Strong SMOC years

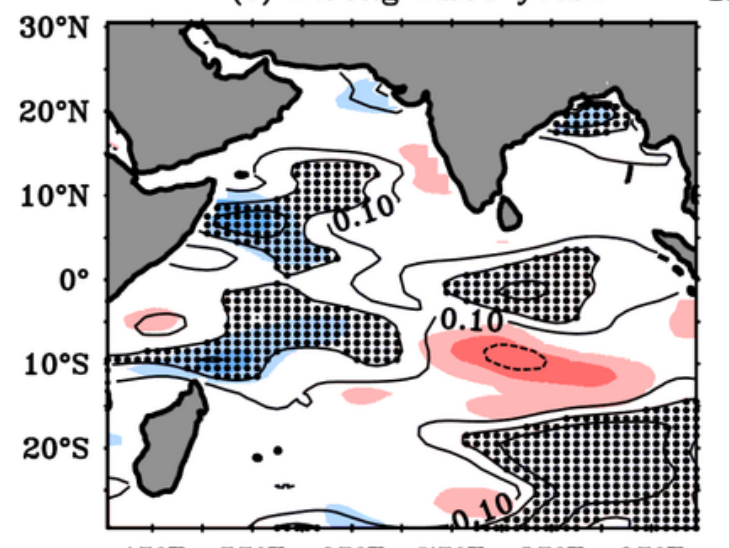

$45^{\circ} \mathrm{E} \quad 55^{\circ} \mathrm{E} \quad 65^{\circ} \mathrm{E} \quad 7^{\circ} \mathrm{E} \quad 8^{\circ} \mathrm{E} \quad 95^{\circ} \mathrm{E}$
SODA

(b) Weak SMOC years

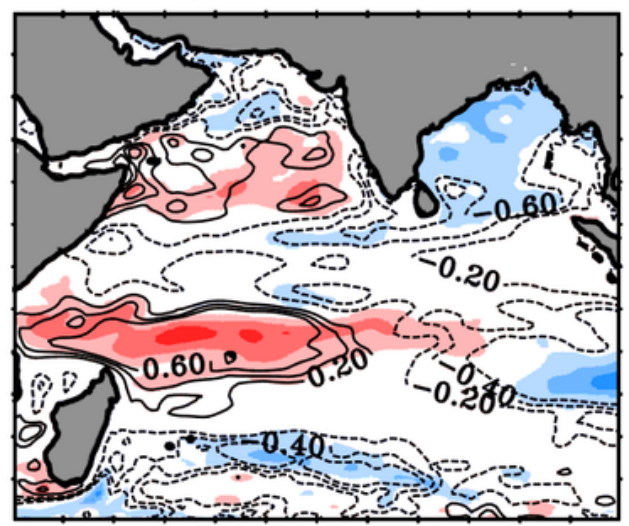

EN4

(d) Weak SMOC years

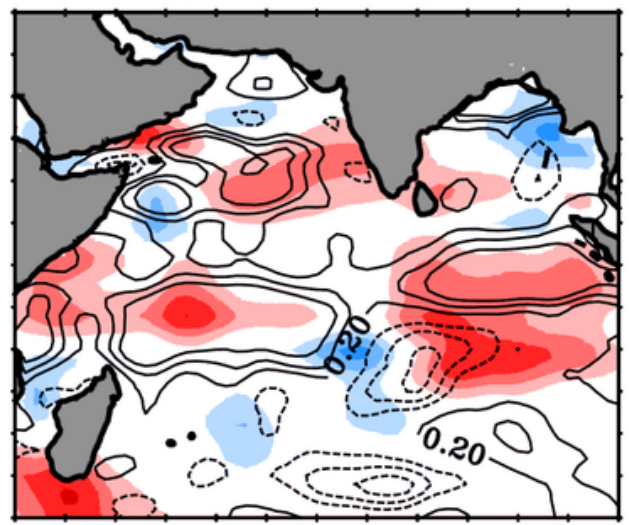

Ishi

(f) Weak SMOC years

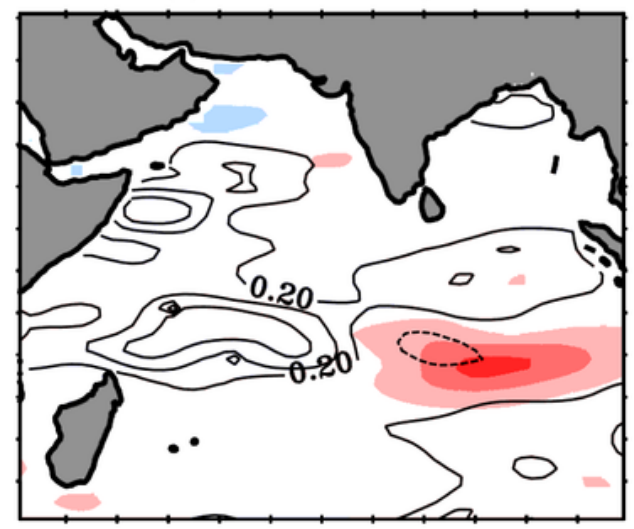

$\begin{array}{llllll}45^{\circ} \mathrm{E} & 55^{\circ} \mathrm{E} & 65^{\circ} \mathrm{E} & 75^{\circ} \mathrm{E} & 85^{\circ} \mathrm{E} & 95^{\circ} \mathrm{E}\end{array}$

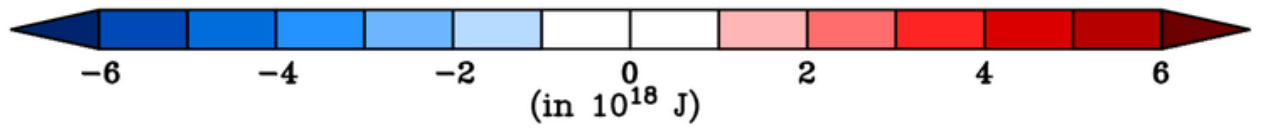

Figure 6

Composite of 200m Ocean Heat Content anomaly (in $1018 \mathrm{~J}$ ) during strong and weak SMOC years from $\operatorname{SODA}(a, b)$, EN4 (c,d) and Ishi (e,f) during the period 1871-2010, 1959-2010, 1945-2010, respectively. The contour in the first column represents the correlation between OHC 200 and SMOC variability during respective periods. The dot denotes the correlation above $90 \%$ significance level. The contours in the 

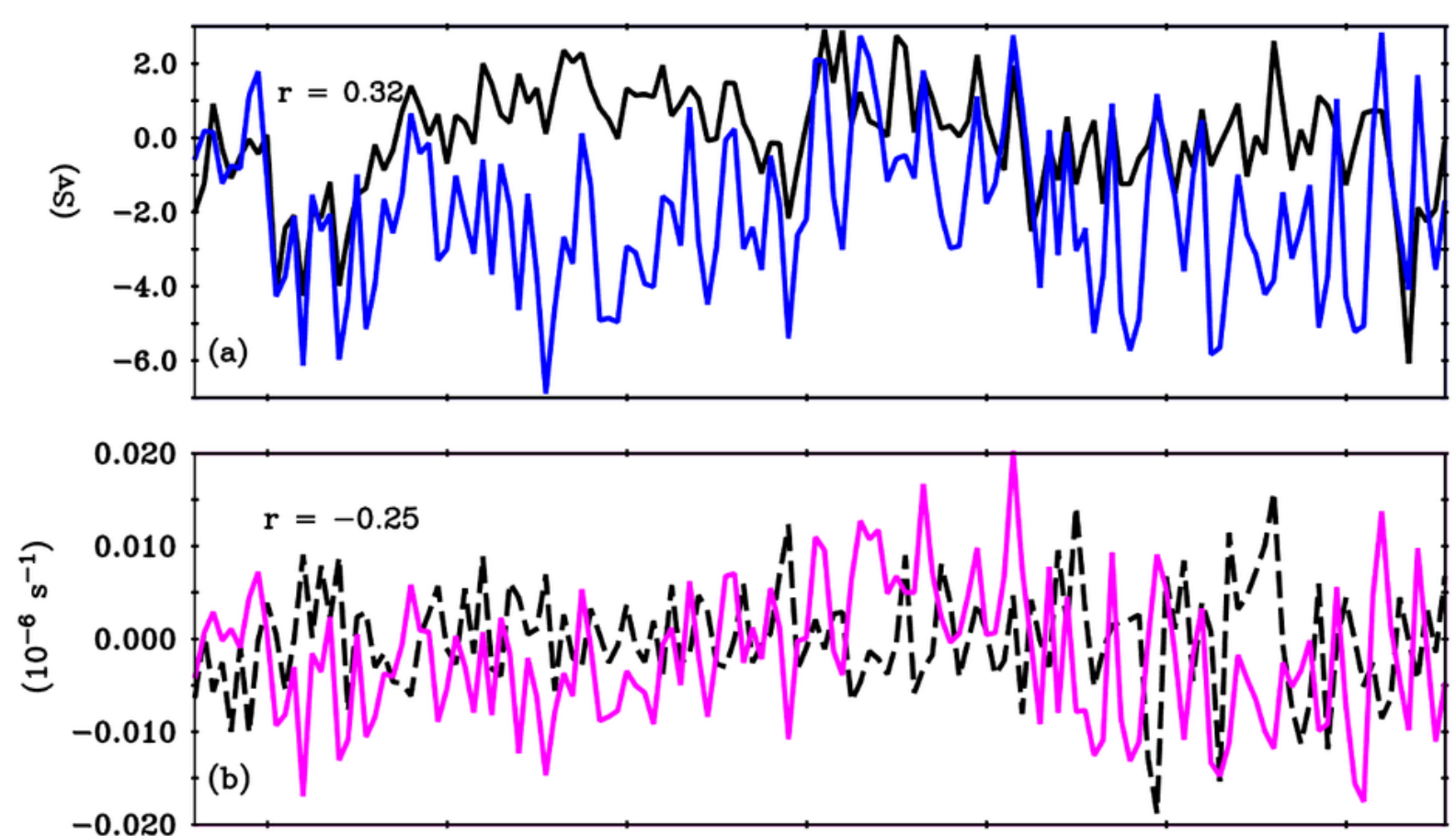

18.

12.
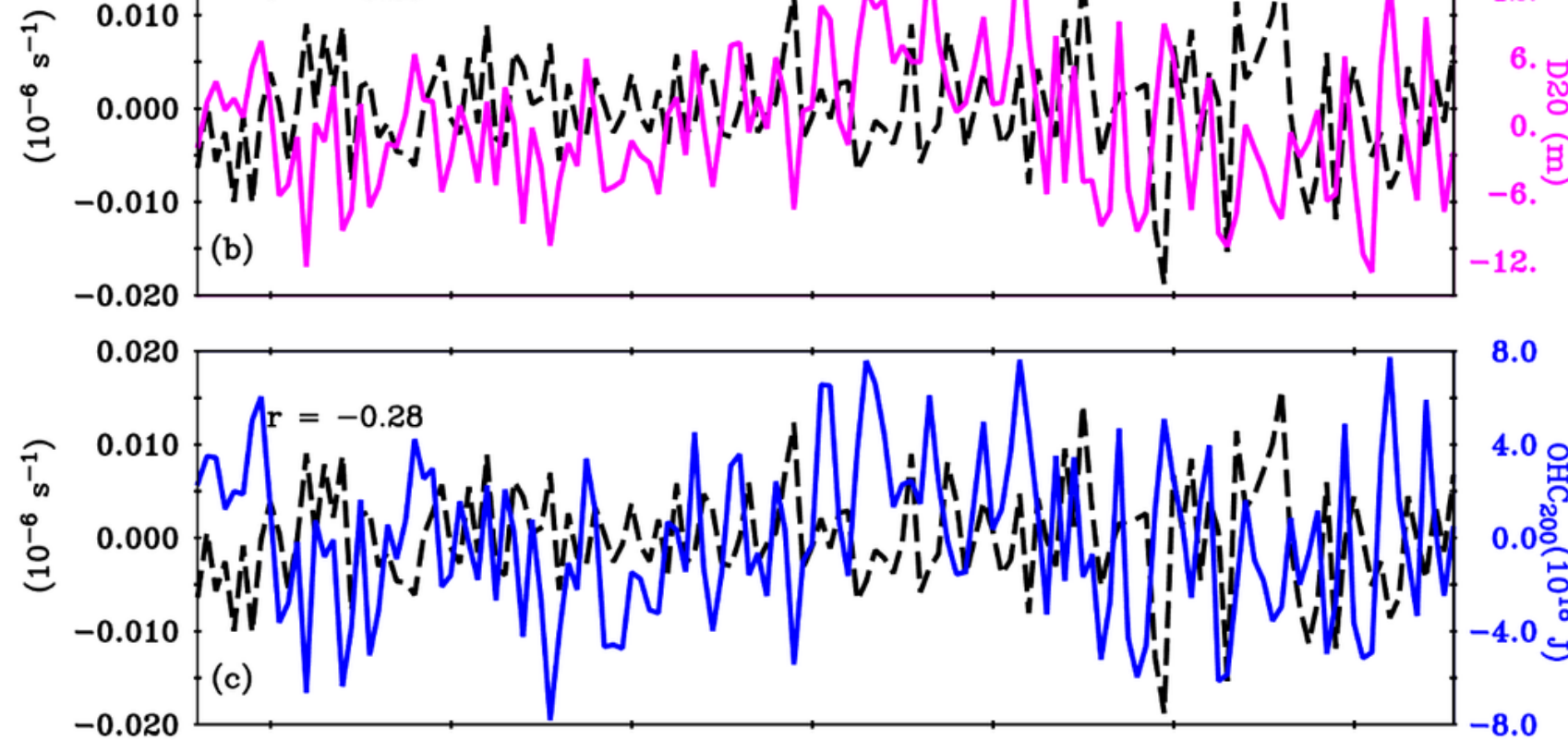

8.0

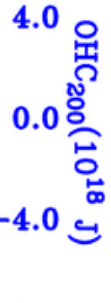

0 
period 1871-2010. The black dashed line connected in by triangle in (d) denotes the sea level anomalies obtained from AVISO data for the period 1993-2010. The red line connected with dots in (d) denotes the annual mean tide gauge measurements $(\mathrm{m})$ obtained from the Madagascar station NOSY-BE (13.40S, 48.3oE) during the period 1958-1972. The correlation coefficient is also given.
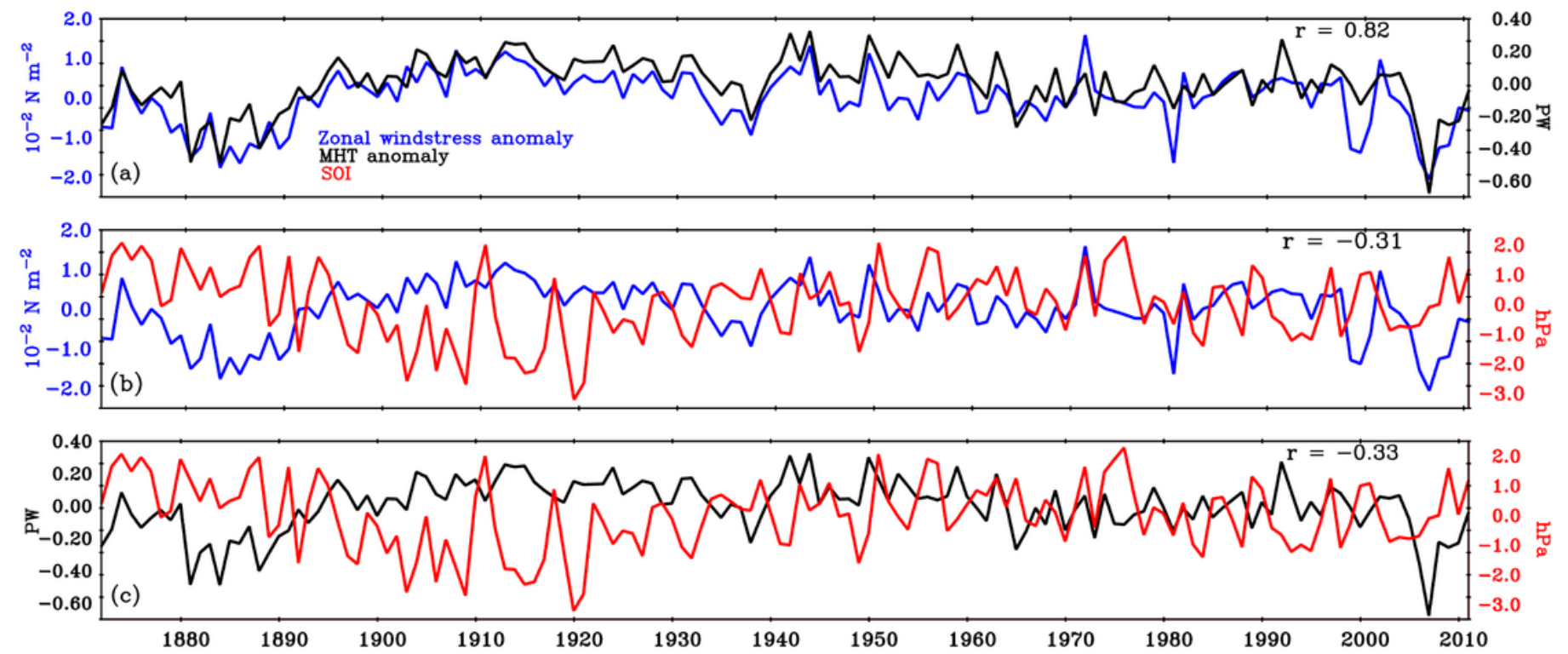

\section{Figure 8}

(a) Time series of upper 60m Meridional Heat Transport (MHT) anomaly (black, in PW) and zonal wind stress anomaly (blue, 10-2 N m-2), (b) Variability in Southern Oscillation Index (SOI) and zonal wind stress anomaly and (c) Time series of MHT and SOI index during the period 1871-2010. 


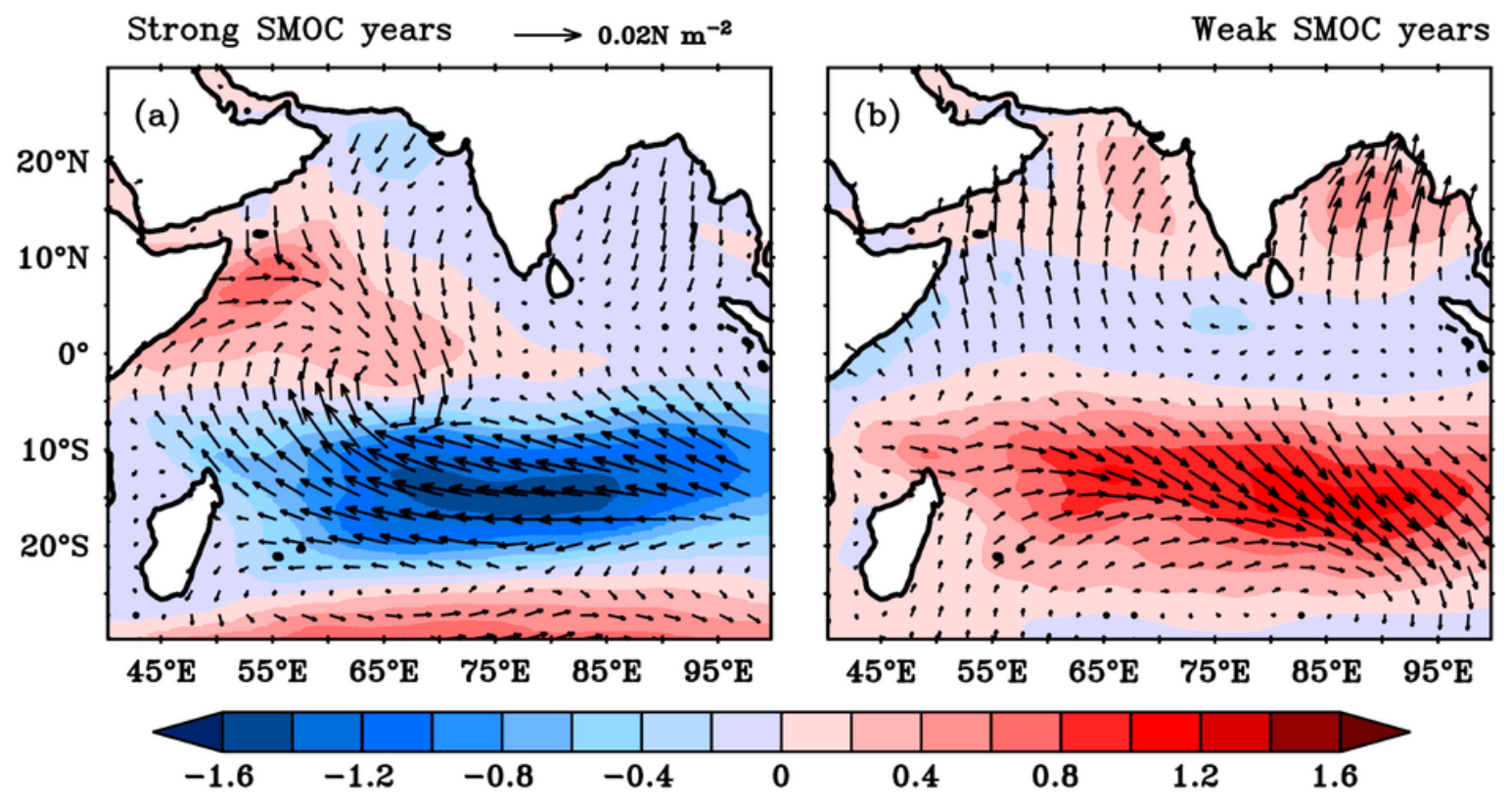

Figure 9

Composite of zonal wind stress anomaly (shaded, 10-2 Nm-2) and wind stress (vectors) for (a) strong and (b) weak SMOC years during the period 1871-2010 
(a) Strong SMOC years

$0.5 \mathrm{~m} / \mathrm{s}$

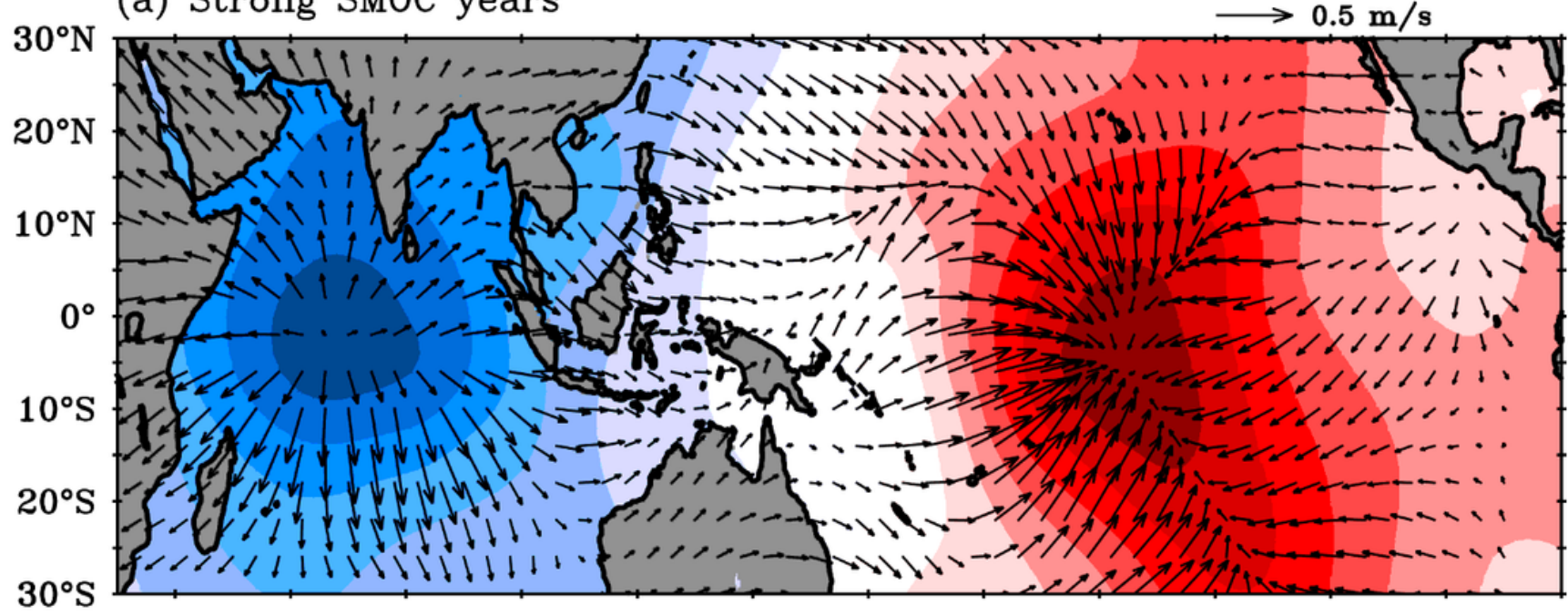

(b) Weak SMOC years

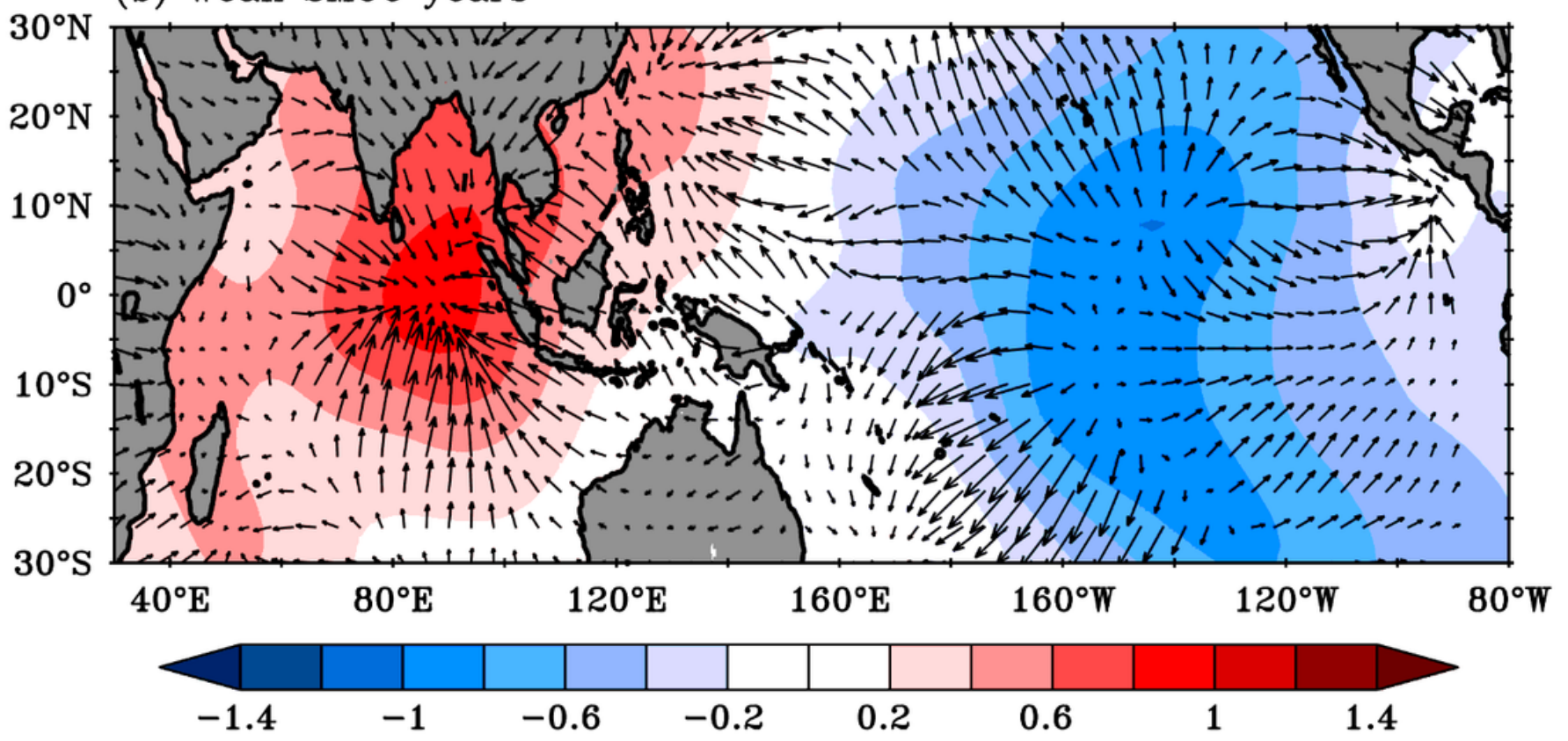

Figure 10

The composite of velocity potential (shaded, $106 \mathrm{~m} 2 \mathrm{~s}-1$ ) and divergent wind anomalies (vector, ms-1) at 200hpa for strong (a) and weak (b) SMOC years during the period 1871-2010. 
(a) Strong SMOC years $\longrightarrow 0.009 \mathrm{~m} / \mathrm{s}$ CTRL

(b) Weak SMOC years
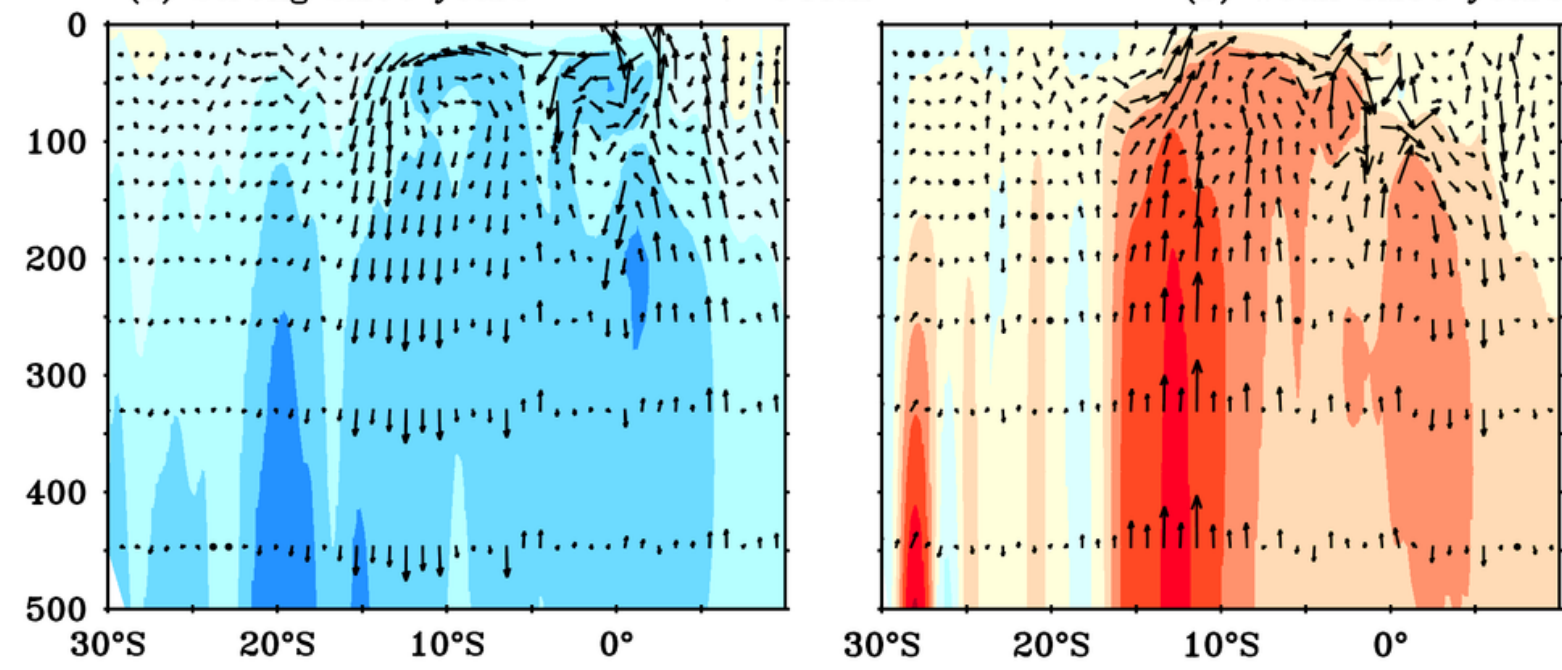

(c) Strong SMOC years

IOSMOC

(c) Weak SMOC years
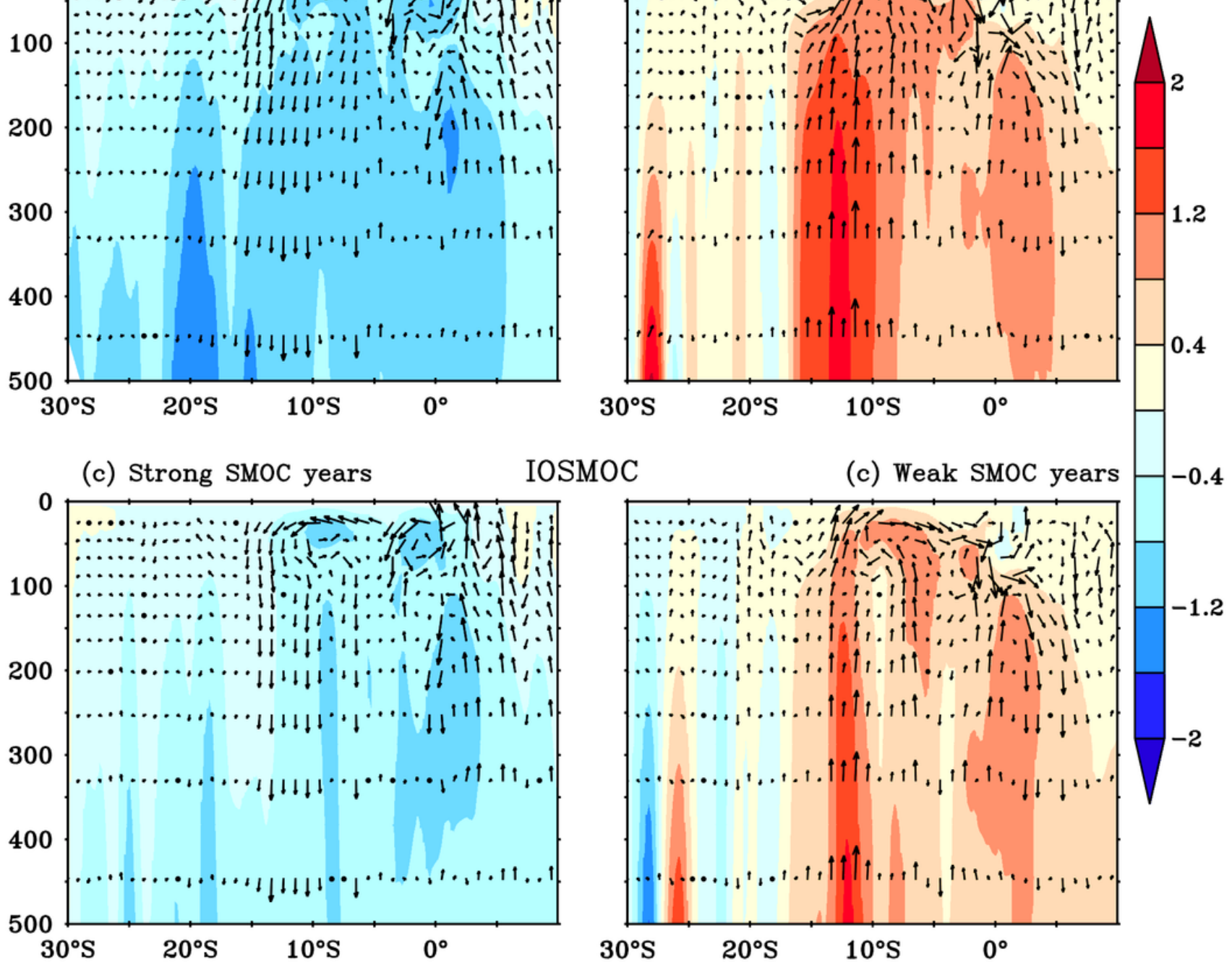

\section{Figure 11}

Composite of Meridional Overturning Stream function anomaly (Sv, shaded) and anomalous SMOC (m s1 , vectors) during strong $(a, c)$ and weak years $(b, d)$ from CTRL and IOSMOC experiments during the period 1960-2009. It is important to note that the vertical current is multiplied by a factor of 104 . 
(a) Strong SMOC years

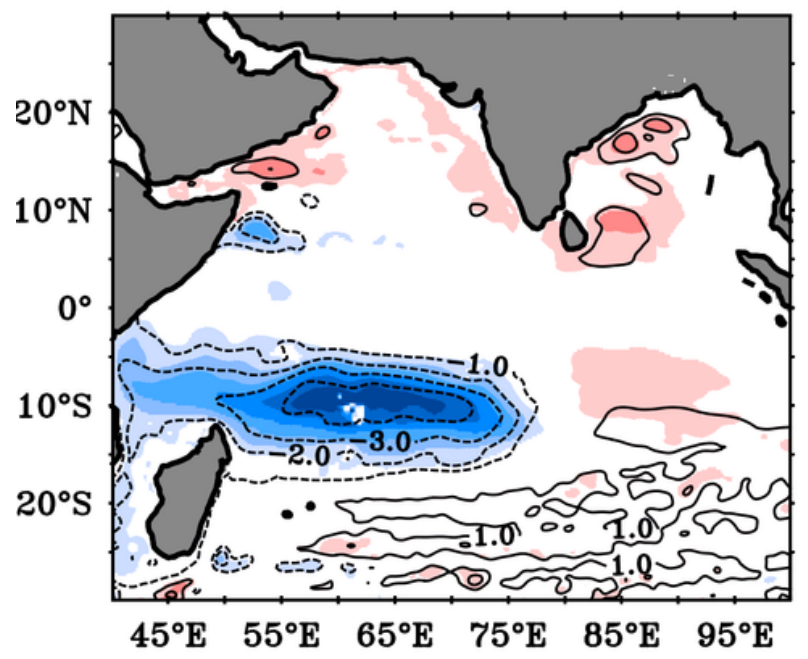

CTRL

(b) Weak SMOC years

(c) Strong SMOC years

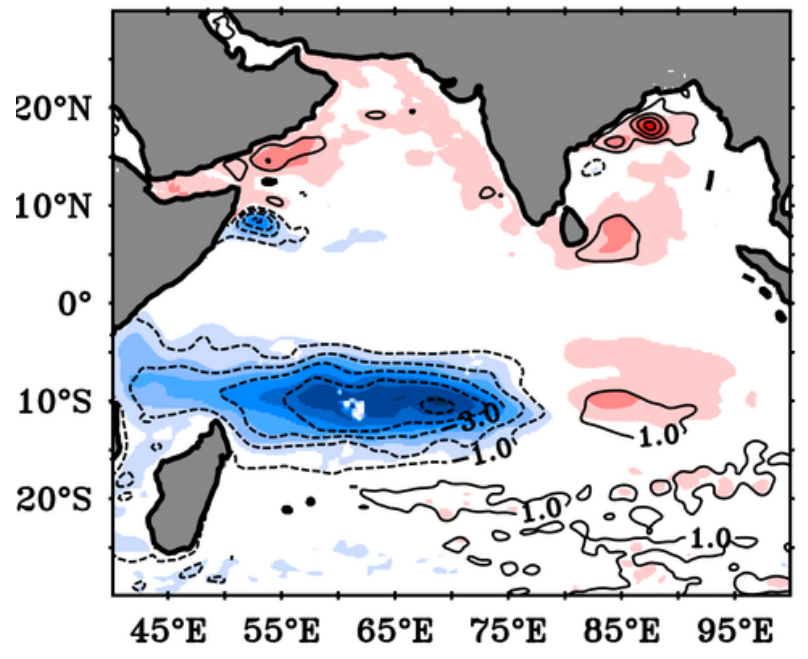

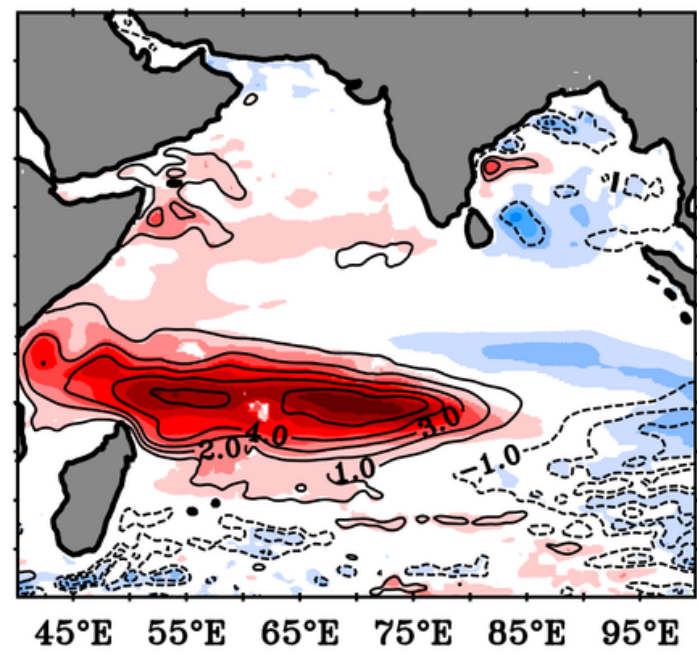

(d) Weak SMOC years

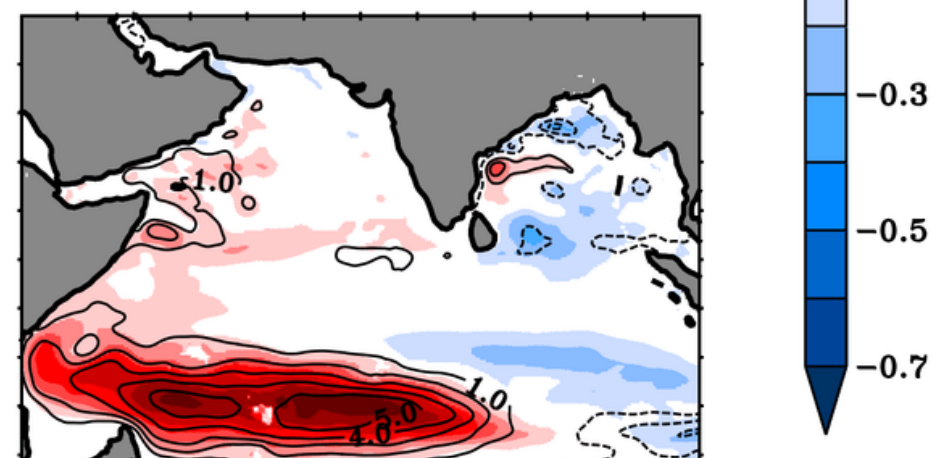

Figure 12

Composite of upper $200 \mathrm{~m}$ ocean heat content anomaly (shaded, $109 \mathrm{~J} \mathrm{~m}-2$ ) and sea level anomaly (contour, $\mathrm{cm}$ ) during strong $(\mathrm{a}, \mathrm{c})$ and weak $(b, d)$ years from CTRL and IOSMOC experiments respectively. 